\title{
THE EFFECT OF MUSCULOSKELETAL INJURY ON ENDOGENOUS NANDROLONE METABOLISM
}

\author{
Submitted by: Dr. R.M.N Kohler (KHLRYA001) \\ Supervised by: Professor M.I.Lambert
}

MRCIUCT RESEARCH UNIT FOR EXERCISE SCIENCE AND SPORTS MEDICINE, DEPARTMENT OF HUMAN BIOLOGY, FACULTY OF HEALTH SCIENCES, UNIVERSITY OF CAPE TOWN, SOUTH AFRICA.

Submitted in partial fulfillment of the requirements for the Master of Philosophy degree in Sports Medicine (MPhil Sports Medicine). 
The copyright of this thesis vests in the author. No quotation from it or information derived from it is to be published without full acknowledgement of the source. The thesis is to be used for private study or noncommercial research purposes only.

Published by the University of Cape Town (UCT) in terms of the non-exclusive license granted to UCT by the author. 


\section{DECLARATION}

I, Ryan Kohler, hereby declare that the work on which this dissertation is based is my original work (except where acknowledgements indicate otherwise) and that neither the whole work nor any part thereof, is being, or is to be submitted for another degree in this or any other university.

No part of this dissertation may be reproduced, stored in a retrieval system or transmitted in any form or means without prior permission in writing from the author or the University of Cape Town.

Signature: Signed by candidate

Date: 


\section{ACKNOWLEDGEMENTS}

- Professor Mike Lambert for his guidance, encouragement and valuable assistance in making this project thoroughly enjoyable and an incredible learning experience. Thank you for shaping my career in sports medicine and challenging me on an ongoing basis to achieve my goals.

- Theresa van Jaarsveld and Gretha Hopkins, Pathcare Laboratories, Milnerton, Cape Town for their dedication, efficiency and enthusiasm while processing and analyzing the blood samples collected during the study.

- Keith Hall (Manchester, United Kingdom) for generously giving of his time and facility for the analysis of the urine samples and Dr. Simon Davis for helping with the sample analysis and co-authoring the description of the steroid analytical methods.

* Dr. Basil Bonner, Emergency Unit, Milnerton MediClinic for facilitating the study in the trauma unit and creating awareness for the recruitment of study subjects.

- Mr. Andy Turner, past manager of Milnerton MediClinic Hospital, for the funding and sponsorship in couriering the urine samples to the United Kingdom.

- This study was supported in part by funds from the University of Cape Town.

- Mom, Dad, and Angela for the support and encouragement throughout the 4 years of study and thesis. I am truly blessed to have such a fantastic family. 


\section{TABLE OF CONTENTS}

Page

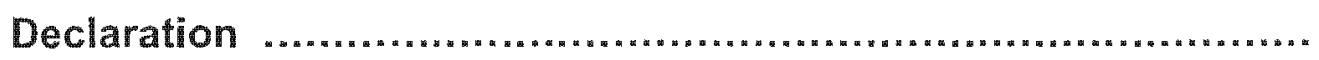

Acknowledgements

Table of Contents

4

List of Abbreviations

List of Tables

List of Figures

Abstract

Chapter 1: Motivation and Aims of the study

1.1 Introduction

1.2 Aims of the thesis

1.3 Research question

Chapter 2: Review of endogenous nandrolone metabolism.

2.1 Introduction 14

2.2 Evidence for endogenous 19-norandrosterone.................... 15

2.3 Metabolism of 19-norandrosterone.................................... 17

2.4 Factors with the potential to affect 19-norandrostrone metabolism ... $\quad 19$

2.5 Challenging the IOC cut-off concentration for urine 19-norandrosterone... 25

2.6 Methods to test for 19 norandrosterone. 26 
Chapter 3: The effect of musculoskeletal injury on endogenous nandrolone metabolism.

3.1 Abstract.

3.2 Introduction

3.3 Methods.

3.4 Results

3.5 Discussion

Chapter 4: Summary and Conclusion

References

\section{Appendices}

Appendix A:

Informed consent-English.

Appendix B:

Informed consent - Xhosa.

Appendix $C:$

Informed consent - Afrikaans

Appendix D:

Exclusion Criteria.

Appendix E:

Demographic information and health assessment...

Appendix F:

Training history and training diary....

Appendix G:

Urine nandrolone metabolites: false positive doping test?

Br J Sports Med 2002; 36:325-329

Appendix H:

Ethics approval letter from the University of Cape Town... 


\section{List of abbreviations}

- Adrenocorticotrophic hormone

ACTH

- Anabolic androgenic steroids

AAS

- Body Mass Index

BMI

- Dehydroepiandrosterone

DHEA

- Gas chromatography isotope ratio mass spectrometry

GC- C-IRMS

- Gas chromatography mass spectrometry

GC-MS

- Hypothalamic pituitary axis

HPA

- Injury severity score

ISS

- International Olympic Committee

100

- Level Of Detection

LOD

- Luteinizing hormone

LH

- mass and charge

$\mathrm{m} / \mathrm{z}$

- nanogram per milliliter

$n g . m l^{-1}$

19-norandrosterone

19-NA

- 19-noretiocholanolone

19-NE

- picogram per milliliter

pg. $\mathrm{mi}^{-1}$ 


\section{List of tables}

Table 3.1 Descriptive characteristics of the subjects $(n=32)$

Table 3.2 Descriptive characteristics of the injuries $(n=32)$

Table 3.3 The time of the musculoskeletal injury and urine sample collection in the subjects.

Table 3.4 Plasma cortisol and LH responses in male subjects post-injury $(n=32)$.

Table 3.5 Urine characteristics in male subjects after sustaining musculoskeletal injury ( $n=32$ ).

Table 3.6 Urinary 19-NA and 19-NE concentrations immediately post-injury and at baseline

Table 3.7 Urinary 19-NA and 19-NE concentrations for Sub-group $A(n=20)$ and Sub-group $B(n=12)$ 


\section{List of figures}

Page

Figure 2.1 The androgen biosynthetic pathway and the proposed aromatisation of androgen to oestrogen with the formation of 19-norsteroid intermediates.

Figure 3.1a Single ion monitoring spectrograph mass chromatogram $(\mathrm{m} / \mathrm{z} 405)$ of the 19-NA and 19-NE content of an athlete's urine following acute musculoskeletal injury.

Figure 3.1b Single ion monitoring mass chromatogram $(\mathrm{m} / \mathrm{z} 405)$ of the $19-\mathrm{NE}$ content of an athlete's urine following acute musculoskeletal injury.

Figure 3.1c Single ion monitoring spectrograph $(\mathrm{m} / \mathrm{z} 405)$ of the 19-NA and 19-NE content of an athlete's urine following acute musculoskeletal injury. 38

Figure 3.2 Inter-individual variation in plasma cortisol concentrations post-injury.

Figure 3.3 Plasma cortisol concentrations (mean \pm SD) post-injury are compared to baseline.

Figure 3.4 Inter-individual variation in plasma $\mathrm{LH}$ concentrations post-injury... 43

Figure 3.5 Inter-individual variation in urinary 19-NA concentrations at baseline (a) and post-injury (b)

Figure 3.6 Urine 19-NE (pg. ml ${ }^{-1}$ ) post-injury and at baseline (a) and urine 19-NA (pg. $\mathrm{ml}^{-1}$ ) post-injury and at baseline $(\mathrm{b})(\mathrm{n}=32)$. $* \mathrm{P}<0.05$ (all data included). 
Figure 3.7 Inter-individual variation in urinary 19-NE concentrations at

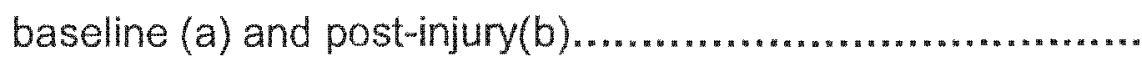




\begin{abstract}
Two elite international male athletes tested positive for nandrolone after both sustaining a severe musculoskeletal injury. Both athletes denied the intentional use of nandrolone. No previous study has investigated the effect that a severe physiological stress in the form of musculoskeletal injury can have on the excretion of nandrolone metabolites (19-NA and 19-NE) in the urine of athletes. Accordingly, the first phase of this thesis involved a review of the literature. This review showed that there is a theoretical basis for the excretion of nandrolone metabolites in the urine to be altered by various physiological stimuli. Therefore the main aim of the thesis was to validate the International Olympic Committee's cut-off concentration for nandrolone metabolites (19-NA and 19-NE) in the urine of male athletes $\left(2000 \mathrm{pg} \cdot \mathrm{ml}^{-1}\right)$. Other aims of the thesis were to determine if musculoskeletal injury can increase the concentration of nandrolone metabolites in the urine of normal subjects and to confirm the endogenous production of 19-NA and 19-NE in the urine of athletes free of exogenous nandrolone. The results were that one of the injured subjects, free of synthetic nandrolone, produced a $19-\mathrm{NA}$ concentration of $2800 \mathrm{pg} \cdot \mathrm{ml}^{-1}$ (IOC cut-off $=$ $\left.2000 \mathrm{pg} \cdot \mathrm{ml}^{-1}\right)$. This finding represents a false positive doping test for nandrolone and will require further similar studies to validate this finding. Also, musculoskeletal injury did not result in a significant increase in 19-NA or 19-NE concentrations in the urine when compared to baseline. This study confirms the endogenous production of small amounts of 19-NA and 19-NE in subjects not administering synthetic nandrolone. In accordance with this, multi-centre studies need to further answer specific questions regarding the current urine threshold concentrations for nandrolone metabolites and whether physiological stressors like musculoskeletal injury can affect nandrolone metabolite excretion.
\end{abstract}

Key words: nandrolone, aromatisation, musculoskeletal injury, injury severity score, 19-norandrosterone (19-NA), 19-noretiocholanolone (19-NE) 


\section{Chapter 1}

\section{Motivation and aims of the thesis}

\subsection{Introduction}

Nandrolone (19-nortestosterone) is a derivative of the naturally occurring anabolic steroid hormone testosterone found in humans. Testosterone is important in the development of secondary sexual characteristics in males. ${ }^{29}$ Nandrolone was first synthesized in $1950{ }^{51}$ and has become a popular anabolic androgenic steroid (AAS) amongst sportspersons. ${ }^{32 ; 89}$ Nandrolone is reportedly able to increase lean muscle mass and improve strength gains, thereby enhancing athletic performance. ${ }^{67}$ At the same time, very few significant side effects have been reported, thus contributing to its popularity. The International Olympic Committee (IOC) banned the use of nandrolone in sporting competition in 1976 and in 1985 introduced gas chromatography mass spectrometry (GC-MS) with a level of detection of $2 \mathrm{ng} \mathrm{ml}^{-1}$ to test for the metabolites (breakdown products) of nandrolone in the urine of athletes. The three metabolites of nandrolone are 19-norandrosterone ( 3 alpha-hydroxy-5 alpha-estran-17-one), 19noretiocholanolone ( 3 alpha-hydroxy- 5 beta-estran-17-one) and $19-$ norepiandrosterone ( 3 beta-hydroxy-5 alpha-estran-17-one). ${ }^{57717 ; 59 ; 67 ; 78}$ At that time the detection of any nandrolone metabolite in the urine of an athlete was considered to constitute a doping offence. In 1996, more sensitive testing was introduced at the Winter Olympic Games in Nagano, Japan, using a device capable of measuring 19norandrosterone (19-NA), the most abundant metabolite of nandrolone ${ }^{5 ; 17 ; 59 ; 67 ; 78}$, to a level of detection $0.02 \mathrm{ng} \cdot \mathrm{ml}^{-1}{ }^{36}$ At this time, the $\mathrm{lOC}$ issued a statement announcing that 19-NA concentrations in the urine of male subjects below $2 \mathrm{ng} \cdot \mathrm{ml}^{-1}$ would not constitute a doping offence. ${ }^{82}$ This decision may have been based on the finding of a 
small amount of 19-NA in the urine of many athletes at the Nagono Winter Olympics who had not used nandrolone. Therefore, a cut-off concentration in the urine for 19NA of 2 ng. $\mathrm{ml}^{-1}$ in male athletes and $5 \mathrm{ng} \cdot \mathrm{ml}^{-1}$ in female athletes was established. ${ }^{82}$ It should be noted that this decision was taken by the IOC prior to any controlled scientific studies being performed to validate the cut-off concentration of 19-NA in the urine. This became important when subsequent independent scientific studies confirmed the endogenous production of small amounts of 19-NA in the urine of resting and athletically active populations. $10 ; 20 ; 28 ; 28 ; 43 ; 48 ; 51 ; 72 ; 75 ; 79 ; 93$ The origin of the endogenous 19-NA may be the aromatisation reaction of testosterone to estrogen. $7: 10 ; 20: 21 ; 40 ; 62 ; 72 ; 73 ; 86 ; 90 ; 93$ Further, Reznik et al (2001) has shown that this aromatisation reaction can be upregulated by administering human chorionic gonadotropin which

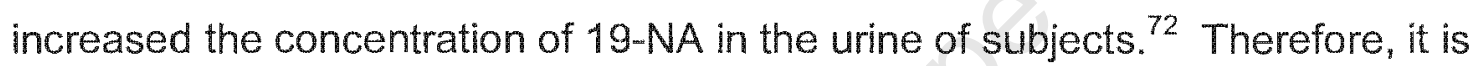
relevant to establish whether any physiological processes in the human body, which can potentially affect testosterone metabolism and aromatisation, may affect the production and excretion of endogenous 19-NA. These possibilities were not considered by the $10 \mathrm{C}$ when deciding on the cut-off concentration of $2 \mathrm{ng} \cdot \mathrm{ml}^{-1}$ in male subjects. Various physiological processes have been proposed as having an effect on the excretion of nandrolone metabolites in the urine. Certain forms of exercise have the potential to affect testosterone metabolism. $45 ; 46 ; 55 ; 80 ; 87 ; 94 ; 95$ The results of studies investigating the effect of exercise on the excretion of 19-NA in the urine have showed mixed results. It seems that the intensity of the exercise may be an important factor in predicting whether exercise will increase the excretion of 19-NA in the urine. 
Recently, two high-profile nandrolone doping cases involved athletes who had sustained severe musculoskeletal injury before passing a urine sample. This has raised the possibility that severe physiological stress in the form of musculoskeletal injury may affect the excretion of 19-NA in the urine of athletic individuals free of synthetic nandrolone. ${ }^{64}$ (Personal communication) No previous study has investigated whether a severe musculoskeletal injury stress can increase the excretion of nandrolone metabolites in the urine of male subjects.

\subsection{Aims of the thesis}

- To validate the International Olympic Committee's cut-off concentration for urine 19-NA of $2 \mathrm{ng} \cdot \mathrm{ml}^{-1}$ in male subjects immediately after sustaining musculoskeletal injury.

- To determine whether moderately active male subjects who sustain severe physiological stress (musculoskeletal injury) can excrete nandrolone metabolites (19-NA and 19-NE) in the urine in higher concentrations compared to baseline.

- To confirm the endogenous production of 19-NA and 19-NE in the urine of moderately active male subjects.

\subsection{Research question}

"Can severe musculoskeletal injury in healthy moderately active male subjects increase the excretion of endogenous nandrolone metabolites in the urine above 2 $n g . m t^{-1} ? "$ 


\section{Review of endogenous nandrolone metabolism}

(Br J Sports Med 2002; 36:325-329)

\subsection{Introduction}

The anabolic androgenic steroid 19-nortestosterone, also called nandrolone, was first synthesized by Birch in $1950 .{ }^{51}$ Nandrolone has an anabolic effect, and is used in the treatment of certain chronic diseases. ${ }^{22,51,76}$ The use of nandrolone by athletes became popular in the late 1950's. ${ }^{32}$ Athletes use nandrolone in an oral or injectable form to increase muscle strength and improve performance. ${ }^{47}$ As a result of the potential performance enhancing benefits ${ }^{89}$ and potential health risks associated with anabolic steroid use, ${ }^{34}$ the International Olympic Committee (10C) prohibited the use of nandrolone in sport in 1976.

When nandrolone is ingested or injected by human subjects, three metabolites of nandrolone are isolated and measured in the urine using gas chromatography-mass spectrometry (GC-MS). These metabolites have been identified as 19norandrosterone (3 alpha-hydroxy-5 alpha-estran-17-one), 19-noretiocholanolone (3 alpha-hydroxy-5 beta-estran-17-one) and 19-norepiandrosterone ( 3 beta-hydroxy-5 alpha-estran-17-one). 5;7:17;59;67;78 These metabolites are isomeric compounds, having the same chemical composition and molecular weight, but different chemical structure. 19-Norandrosterone (19-NA) is usually the most abundant urine metabolite of nandrolone. ${ }^{5 ; 17 ; 59 ; 67 ; 78}$ The presence of these metabolites in the urine forms the basis of doping analysis for the illegal use of nandrolone by athletes. $177,20,78,91$ This was based on the premise that these urine metabolites could only have been derived from exogenous nandrolone. A study in 1982 was suspected measuring $19-\mathrm{NA}$, or a similar compound, in the urine of individuals who had not used nandrolone. ${ }^{7}$ In 1996 , 
the IOC stated that a critical concentration for nandrolone metabolites in the urine had been established. A doping offence for nandrolone was defined as a concentration of 19-NA in human urine exceeding $2 \mathrm{ng} \cdot \mathrm{ml}^{-1}$ in men and $5 \mathrm{ng} \cdot \mathrm{ml}^{-1}$ in women. ${ }^{82}$

Recently, questions have been raised regarding possible false positive tests for nandrolone. Explanations for false positive tests have been attributed to a risk of supplement contamination ${ }^{90}$ or endogenous production of nandrolone and regulation of metabolic pathways of nandrolone metabolism by various physiological factors and supplement interventions. The aim of this review is to critically analyze the studies on nandrolone metabolism with the overall goal of determining whether it is indeed possible for an athlete to test positive for nandrolone without having either ingested or injected nandrolone. The question of a positive test arising from nutritional supplements ${ }^{1 ; 10}$ and food contamination ${ }^{18 ; 50}$ is beyond the scope of this review.

\subsection{Evidence for endogenous 19-norandrosterone}

The origin of endogenous 19-NA found in the urine of athletes not having knowingly ingested or injected nandrolone is central to resolving the question of whether it is possible to have a false positive test. The first study to suggest that 19-NA could be found in the urine of individuals free of exogenous nandrolone was a study on laboratory staff $(n=14),{ }^{7}$ Their urine was analyzed using isotope dilution-mass spectrometry and 19-NA or a similar compound was suspected. This suspicion was based on the detection of a small peak for the ion at $\mathrm{m} / \mathrm{z} 256 .{ }^{7}$ In retrospect, this signal may have been caused by interference of other endogenous compounds (noise) and perhaps represents a false positive finding. The authors acknowledged 
the limitations of the study because the analytical technique lacked specificity and sensitivity.

Studies published in 1988 and 1990 again raised the possibility of endogenous 19-NA appearing in the urine of humans. Kicman and Brooks (1988) used radioimmunoassay and measured 19-NA in the urine of men and women, supposedly free of exogenous nandrolone, ranging from 3.8 to $49.4 \mathrm{ng} \cdot \mathrm{ml}^{-1}$. ${ }^{40}$ However, these data should be interpreted with caution as it could be argued that the analytical technique again lacks both specificity and sensitivity. Debruyckere et al. (1990) measured 19-NA in the urine of three individuals at concentrations of 9, 14 and 37 ng. $\mathrm{ml}^{-1}$ respectively. ${ }^{17}$ These results were later attributed to nandrolonecontaminated meat, which the subjects may have eaten. ${ }^{18 ; 19}$

In 1996, the IOC declared that the presence of a small amount of 19-NA in the urine was not considered to constitute a doping offence. ${ }^{82}$ This suggests that the authoritative body acknowledged the possibility of endogenous 19-NA production. It can only be assumed that this decision was reached based on the data collected by IOC laboratories during routine drug testing as the scientific evidence at the time was equivocal. In the late 1990's, analytical testing procedures for the detection and quantification of steroid metabolites in urine had become increasingly sensitive. ${ }^{36}$ This may have accounted for a significant number of positive urine samples for 19-NA being analyzed in certain anti-doping laboratories. Many of the positive samples were from the participants of sports that had previously not been associated with anabolic steroid use. ${ }^{51}$ Further research with more sensitive equipment was undertaken to determine whether NA could be produced naturally by the human body. This research 
showed convincing evidence that 19-NA was found in the urine of individuals free of exogenous nandrolone. 10;20;28;28;43;48;51;72;75;79;93 The 19-NA urine concentrations in these studies ranged from $0.01-1.79 \mathrm{ng} \cdot \mathrm{ml}^{-1}$. In a study by Galan Martin et al. (2001), high 19-NA concentrations in five sportspersons $\left(4,5,6,8,14 \mathrm{ng}_{\mathrm{ml}} \mathrm{m}^{-1}\right)$ were measured. One woman in the study, who was post-menopausal, had a 19-NA concentration of $22 \mathrm{ng} \cdot \mathrm{ml}^{-1}$. It could be argued that these athletes had administered nandrolone. ${ }^{27}$ These results are difficult to explain and perhaps further investigation of these subjects is necessary before a definite opinion can be formed.

\subsection{Metabolism of 19-norandrosterone}

\section{Aromatisation}

Metabolic pathways for the endogenous production of 19-NA in the human body need to be considered. Under normal circumstances, testosterone is aromatised to estrogen by the aromatase enzyme complex. ${ }^{26}$ Androstenedione, the direct precursor for testosterone, is also aromatised to estrogen by the aromatase enzyme. ${ }^{29 ; 54}$ The important step in this metabolic process is the removal of the nineteenth carbon methyl group (CH3) from either testosterone or androstenedione. Nandrolone differs structurally from testosterone and androstenedione by lacking the methyl group at the nineteenth carbon position and additionally from androstenedione by substitution of a ketone group for a hydroxyl group at the seventeenth carbon position. Could it be feasible that 19-norsteroids (nandrolone and metabolites) are intermediates in the aromatisation process? (Figure. 2.1). 


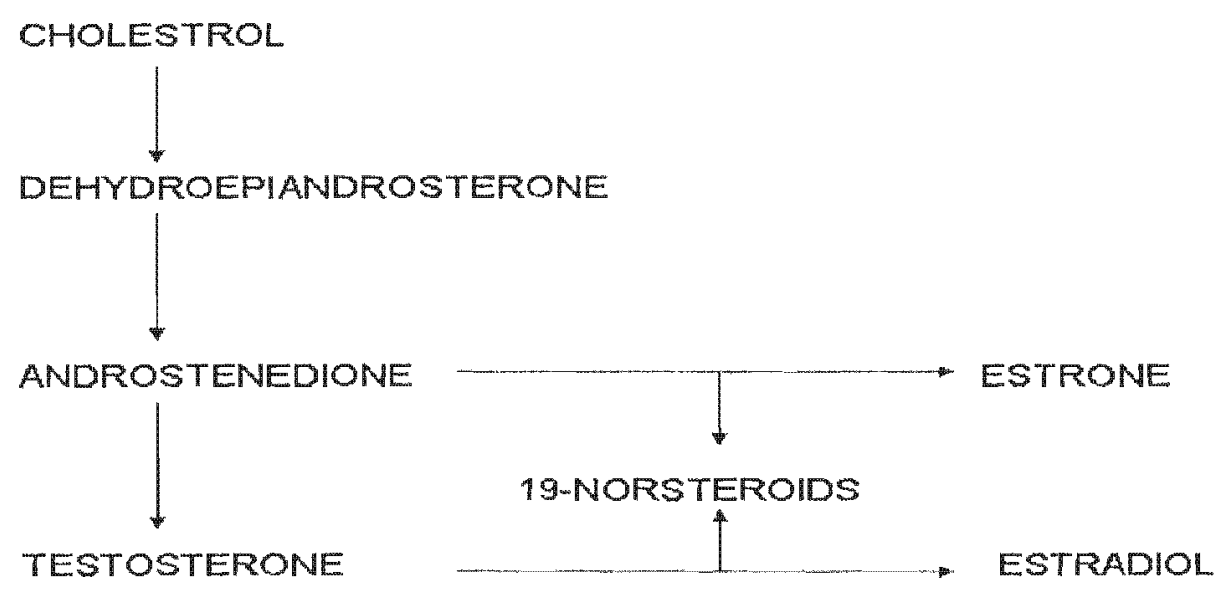

Figure 2.1 The androgen biosynthetic pathway and the proposed aromatisation of androgen to estrogen with the formation of 19-norsteroid intermediates.

Animal studies, in vitro experiments and observations in humans, particularly pregnant females, add support to the proposal that 19-norsteroids are intermediates in the aromatisation of androgens to estrogen. 7:10;20;21:40;62;72;73;86;90;93 Estrogen concentrations in women increase significantly both at the time of ovulation and during pregnancy. ${ }^{57: 93}$ Recently, elevated urine 19-NA levels were identified in women at the time of ovulation ${ }^{31: 93}$ and during pregnancy. ${ }^{93}$ Mareck-Engelke et al. (1998) reported that during pregnancy the concentration of 19-NA in human urine may reach $20 \mathrm{ng} \cdot \mathrm{ml}^{-}$ ${ }^{1 .}{ }^{58}$ In these cases, pregnancy is confirmed with a blood test for human chorionic gonadotropin.

A recent study by Reznik et al. (2001), examined the sequelae after the administration of human chorionic gonadotropin to ten male subjects. ${ }^{72}$ Human chorionic gonadotropin increases serum testosterone in healthy males ${ }^{14 ; 4 ; 84}$ and stimulates the aromatase enzyme causing a gradual increase in serum estrogen. ${ }^{68 ; 70,84}$ The serum 
testosterone and estrogen increased in the ten subjects after human chorionic gonadotropin administration, and 19-NA excretion in the urine increased by $250 \%$. It may be concluded from this study that the increase in nandrolone biosynthesis was possibly associated with the increased aromatisation of testosterone to estrogen.

Although the pathways proposed are theoretical, the available evidence suggests that it is possible that the flux of androgen precursors down the testosterone biosynthetic pathway could result in the production of endogenous nandrolone. Therefore it can be assumed that factors which could increase the flux of androgen precursors down the testosterone biosynthetic pathway could theoretically increase the amount of nandrolone produced.

\subsection{Factors with the potential to affect 19-norandrosterone metabolism.}

\section{Genetics}

There is a wide range for serum testosterone concentrations in men, ${ }^{29}$ suggesting large genetic interindividual and intraindividual variability in sex steroid production and excretion over a 24 -hour period. ${ }^{52}$ In accordance with this, the possibility exists that there is a variable rate of 19-NA excretion. ${ }^{51}$ Indeed, endogenous 19-NA urine excretion in a male athlete varied by $680 \%$ over a three-month period. ${ }^{51}$ Endogenous 19-NA urine excretion varied in another subject by $72 \%$ over a 24 -hour period. ${ }^{20}$ The enzyme complex, 17 beta-hydroxy-steroid dehydrogenase, responsible for converting androstenedione to testosterone and the aromatase enzyme complex, which converts testosterone to estrogen, occur in muscle and fat. ${ }^{35 ; 54}$ Therefore, it is conceivable that individuals with higher muscle and fat content may be more proficient in the 
production of 19-norsteroid intermediates. The aromatase enzyme complex per se can also show marked genetic variability in expression and activity in certain individuals, ${ }^{6}$ with increased activity of the aromatase enzyme producing larger amounts of estrogen. This leads to the question of whether genetic upregulation of the aromatisation process in these individuals increases the production of 19 norsteroids.

\section{Exercise}

Intense exercise has been associated with elevated levels of 19-NA in the urine. 28:48;51;75 Le Bizec et al. (2002) studied professional soccer players over nineteen months and collected 385 urine samples. Urine 19-NA concentrations after soccer games were significantly higher than before games. ${ }^{48}$ For 19-NA concentrations after games, $70 \%$ of the urine samples were below $0.1 \mathrm{ng} \cdot \mathrm{ml}^{-1}, 20 \%$ were between $0.1-0.2$ ng. $\mathrm{ml}^{-1}$. 19-NA in four urine samples was above $1.0 \mathrm{ng} \cdot \mathrm{ml}^{-1}$, the maximum value being $1.79 \mathrm{ng}_{\mathrm{ml}} \mathrm{m}^{-1}{ }^{48}$ A recent study which supported the above hypothesis found that professional football players produced 19-NA in the urine after exercise when compared to sedentary control subjects. ${ }^{28}$ However these data should be interpreted with caution because there was no comment in the study on the measurement of baseline urine 19-NA concentrations in the football players before exercise as urine was collected only after exercise. Therefore, it is not possible to comment on the effect of exercise on urine 19-NA concentration. Further, no mention was made about the hydration status of the football players after exercise, particularly as dehydration may have changed the 19-NA concentration in the urine. Also there was no mention on whether the football players were ingesting nutritional supplements, a known 
source of possible contamination with norsteroid precursors which may also increase the amount of 19-NA in the urine. ${ }^{10 ; 16 ; 16 ; 38 ; 38}$

When urine is tested for banned substances and the specific gravity of the urine sample is measured above 1.020 , urine metabolite concentrations are adjusted by a correction factor. ${ }^{36}$ This analysis is based on the premise that urine flow rate and urine metabolite excretion remain constant during and directly after exercise. However, this is an erroneous assumption as it has been shown that excretion of pseudoephedrine after exercise was increased in subjects in whom urine volume remained constant. ${ }^{30}$ Thus, urine metabolite excretion may not remain constant during and directly after exercise and random urine sample collection after exercise may be unreliable. ${ }^{20: 41}$ A more accurate measure would be to collect a urine sample over a 24-hour period, hence allowing for the calculation of excretion rates of urine metabolites. ${ }^{20}$ However, this is not practical, particularly when testing for drug use in sport.

The serum androgen response to exercise in athletes can vary according to the type, duration and intensity of the exercise task. 45;46:55;80;87;94;95 Serum testosterone, androstenedione and dehydroepiandrosterone (DHEA) concentrations increase with short-term, intense exercise due to increased testicular production by an unknown mechanism. ${ }^{15}$ An increase in serum testosterone after exercise may also be caused by a decrease in the plasma volume ${ }^{96}$ or a decrease in hepatic clearance. ${ }^{95}$ The effect of exercise on serum estrogen is also extremely variable. ${ }^{94}$ 
The hypothesis that exercise may increase the amount of 19-NA in the urine has been challenged in a well controlled laboratory study by Schmitt et al.(2002) who studied male judo players $(n=14)$ and male long distance runners $(n=15) .{ }^{79}$ Baseline urine samples were collected before a 30 second Wingate exercise test and a treadmill running test to exhaustion and then again at 30 minutes, 60 minutes and 24 hours after exercise. It was found that there was a wide variation in the baseline urine 19NA concentrations ranging from undetectable to $0.25 \mathrm{ng} \cdot \mathrm{ml}^{-1}$. Urine $19-\mathrm{NA}$ levels in the two groups did not differ significantly from pre-exercise values. ${ }^{79}$ This study confirms the endogenous production of 19-NA in athletic subjects, however the exercise stress may be considered to be relatively small and therefore not truly representative of longer duration sporting competition stress.

It is conceivable that the increase in circulating androgens in individuals participating in short-duration, high-intensity exercise could result in the stimulation of the aromatase enzyme complex resulting in an absolute increase in the amount of 19-NA appearing in the urine. There are sufficient data ${ }^{28 ; 48 ; 51 ; 75}$ to suggest that a urine specimen collected after high-intensity exercise could have a higher concentration of 19-NA for reasons other than dehydration, but this has recently been challenged in a well conducted laboratory study. ${ }^{79}$

\section{Trauma and hypoglycaemic stress}

As yet, no study has investigated the possible effect that traumatic stress (musculoskeletal injury) may have on 19-norsteroid metabolism. Interestingly, two international male athletes, one an international rugby player ${ }^{64}$ and the other a ParaOlympian (Personal communication), recently tested positive for 19-NA above 2 ng. $\mathrm{m}^{-1}$, after both had suffered significant injuries just prior to passing a urine sample 
for drug testing. Both athletes claimed to be innocent of a doping offence. The concentration of 19-NA in the urine samples of both athletes was approximately 6-8 $\mathrm{ng} \cdot \mathrm{ml}^{-1}$, which is slightly above the $10 \mathrm{C}$ cut-off concentration for men ( $\left.2 \mathrm{ng} \cdot \mathrm{ml}^{-1}\right)$.

Reznik et al. (2001) has provided some insight into the effect of a stress response on nandrolone metabolism. ${ }^{72}$ Hypoglycaemia was induced in ten subjects after receiving $0.11 \mathrm{U} . \mathrm{kg}^{-1}$ of insulin intravenously. Urine samples were collected at $0-2,2-4$ and $4-10$ hours after the insulin injection. They concluded that a hypoglycaemic stress did not significantly alter 19-NA excretion. However, inspection of their data reveals that in certain individuals, 19-NA excretion increased in the first 2 hours after the hypoglycaemic stress was induced. Had the study included more than ten subjects, it is likely there would have been sufficient statistical power to show that the increase in 19-NA in the first 2 hours after a hypoglycaemic stress would have produced a significant finding. Hypoglycaemic stress is associated with the production of glucose counter-regulatory hormones; cortisol, glucagon, growth hormone and adrenaline. ${ }^{29}$ Cortisol is produced in the adrenal cortex when stimulated by adrenocorticotropic hormone (ACTH). ACTH also stimulates the production of androgens and mineralocorticosteroids from the adrenal cortex. ${ }^{29}$ It is tempting to speculate that the increased production of adrenal androgens results in increased 19-NA excretion as described above. Further studies need to evaluate whether the increase in adrenal androgens and their aromatisation could produce any changes in 19-NA excretion after a traumatic musculoskeletal stress. 
Mineral cofactors and herbal products

There is also a theoretical argument for certain substances, which are not prohibited in sport, altering nandrolone metabolism. For example, the trace element zinc is a cofactor in many enzymatic processes in the body. It has been shown that men, who are marginally zinc deficient, have an increase in serum testosterone following zinc supplementation. ${ }^{71}$ Also, diets deficient in zinc resulted in a significant decrease in serum testosterone concentration. Therefore, it can be concluded that zinc supports testosterone production. ${ }^{71}$ Although there is a linear relationship between serum zinc and serum testosterone concentrations, ${ }^{9}$ it is not known whether supraphysiological doses of zinc are associated with higher levels of testosterone production. Certain athletes are marginally zinc deficient $t^{39}$ on the basis of inadequate intake ${ }^{33}$ and significant sweat losses. ${ }^{11 ; 13}$ As zinc status may not be optimal in these athletes, can zinc supplementation enhance testosterone production and could this increase in testosterone production increase the production of aromatisation intermediates? This question was partially addressed when a zinc/magnesium supplement (30 mg zinc) was given to football players nightly for seven weeks. This treatment increased free and bound serum testosterone by approximately $33 \%{ }^{8}$ These findings were not attributed to haemoconcentration as the blood samples were taken 24 hours after exercise. Based on the possibility that 19 -norsteroid metabolism may be associated with testosterone metabolism and the aromatisation process, it is feasible that zinc supplementation, combined with exercise may increase nandrolone metabolites appearing in the urine. 
The herbal product tribulus terrestris (tribestan), which has been used in Eastern cultures since ancient times to treat impotence and improve libido, is another substance which has been associated with an increased serum testosterone concentration. ${ }^{61}$ Could tribestan in combination with exercise increase NA appearing in the urine? Further research into this question is necessary.

\subsection{Challenging the IOC cut-off concentration for urine 19-norandrosterone}

Until recently, studies involving large numbers of subjects to determine the physiological range for the concentration of 19-NA appearing in the urine of men and women free of exogenous nandrolone were lacking. The available data on the range of 19-NA could only be drawn from the analysis of urine from sedentary and recreational sports persons at rest. ${ }^{10 ; 20 ; 43 ; 51 ; 72}$ The total number of subjects from all these studies is approximately one hundred and fifty. No specific mention is made in the studies regarding the age of the male subjects. This is relevant as testosterone production decreases with advancing age. ${ }^{53}$ Therefore, one might expect 19 norsteroid production to also decrease with advancing age, making the age of study populations an important consideration. The amount of 19-NA in the urine from the subjects did not exceed $1 \mathrm{ng} \cdot \mathrm{ml}^{-1}$, except in the study of Galan Martin et al. (2001), in which the concerns have already been raised. ${ }^{27}$

Two recent studies involving larger numbers of sportsmen have provided further evidence. Urine samples collected after exercise in these studies showed that the concentration of 19-NA in the urine increased and in certain individuals the

concentration of 19-NA was close to the cut-off concentration of 2 ng. $\mathrm{ml}^{-1} .{ }^{48 ; 75}$ Should 
this be combined with other stressors and possible supplement interventions (mentioned above), the concentration of 19-NA in the urine is most unpredictable.

The IOC have also apparently collected data and measured 19-NA urine excretion in elite male and female athletes at the 1996 Nagano Olympic Games. However, these data have not been released into the public domain. ${ }^{37}$ It would be beneficial for the $10 \mathrm{C}$ data to be made public to support reasoning behind the calculation of cut-off concentrations for 19-NA in the urine of men and women. There is also no reference by the IOC explaining why the threshold concentration for 19-NA is higher in women. If the reason for the 19-NA concentration being higher in women is due to higher circulating levels of estrogen, particularly at the time of ovulation, is this not indirect support for the presence of 19-norsteroids as intermediates in the aromatisation of androgens to estrogen? ${ }^{93}$ Bradford-Hill has stated: "It is the essence of science to disclose both the data upon which a conclusion is based and the methods by which the conclusion is obtained". ${ }^{63}$

The $10 \mathrm{C}$ has defended the status quo on nandrolone and confirmed these threshold values of $2 \mathrm{ng} \cdot \mathrm{ml}^{-1}$ in men and $5 \mathrm{ng} \cdot \mathrm{ml}^{-1}$ in women in Monaco in October $1999 .{ }^{77}$ The conditions of strict liability are currently applied in the case of any athlete contravening the above thresholds.

\subsection{Methods to test for 19-norandrosterone}

A solution to the controversy surrounding nandrolone in sport is to develop a testing procedure that can accurately differentiate endogenous nandrolone metabolites from nandrolone that is ingested or injected. The technique of gas chromatography- 
combustion-isotope ratio mass spectrometry (GC-C-IRMS) to calculate the ${ }^{13} \mathrm{C} \cdot{ }^{12} \mathrm{C}$ ratio is currently being developed as a method to fulfil this purpose. ${ }^{20 ; 51 ; 60 ; 83}$ This is based on the principle that natural steroids have a different carbon isotopic signature compared to synthetic steroids. The ${ }^{13} \mathrm{C}:{ }^{12} \mathrm{C}$ ratio for synthetic nandrolone metabolites is lower than the ${ }^{13} \mathrm{C}:{ }^{12} \mathrm{C}$ ratio for endogenous metabolites, therefore administering exogenous nandrolone will lower this ratio. This ratio has also been proposed as a method of detection for the use of synthetic testosterone as an alternative to the testosterone:epitestosterone ratio. ${ }^{20 ; 60 ; 83}$ However, a potential problem with GC-CIRMS, is the lack of reproducibility and sensitivity due to the low levels of endogenous nandrolone metabolites present in the body. Presently, this method may orly be applied to 'high' concentrations of 19-NA $\left(60 \mathrm{ng} \cdot \mathrm{ml}^{-1}\right)$ in the urine. ${ }^{60}$

Li Bizec et al. (2002) ${ }^{49}$ has proposed examining the steroid conjugates as an additional criterion to distinguish between the endogenous or exogenous origin of nandrolone metabolites. Endogenous 19-NA was found to be $30 \%$ sulfo-conjugated as opposed to administered nandrolone, which was found to be $100 \%$ conjugated to glucuronic acid when excreted in the urine. ${ }^{49}$

Kintz et al. (2001) ${ }^{44}$ proposed that analysis of hair samples from athletes is another option to consider for detecting the presence of exogenous nandrolone. The analysis of hair samples could be used to accurately verify positive results obtained by GC-MS. $42 ; 44$

Until the hair sample and GC-C-IRMS techniques have been validated on a large scale, a prudent approach after the detection of 19-NA in urine samples above the cut- 
off concentration, is for the athlete to have further blood tests before the sample is declared positive, as is done for athletes with a high testosterone:epitestosterone ratio.

\subsection{Conclusion}

The abuse of the steroid testosterone presented a new problem for drug control in sport. ${ }^{41}$ Perhaps the same can now be said for nandrolone. According to the Olympic Movement Anti-Doping Code, 19-NA is not a prohibited substance. ${ }^{65}$ However, should 19-NA in the urine exceed a certain threshold concentration, the interpretation is that nandrolone has been ingested or injected. There is strong scientific evidence to show that 19-NA appears in the urine of individuals free of exogenous nandrolone. Evidence suggests that 19-NA may occur as an intermediate in the aromatisation of testosterone to estrogen. Recent evidence has shown that the amount of 19-NA in the urine can be regulated by the administration of human chorionic gonadotropin. Therefore, threshold concentrations for men $\left(2 \mathrm{ng} \cdot \mathrm{ml}^{-1}\right)$ and women ( $5 \mathrm{ng} \cdot \mathrm{ml}^{-1}$ ) as defined by the IOC are still open to debate as conclusive scientific evidence showing how these values may be altered by various physiological stimuli is lacking. In accordance with this, multi-centre studies need to further answer specific questions regarding the current urine threshold concentrations for nandrolone metabolites and whether physiological stressors and perrnitted supplement interventions can alter 19-NA excretion. 


\section{Chapter 3}

\section{The effect of musculoskeletal injury on endogenous nandrolone}

\subsection{Abstract}

Background: Two recent high-profile enquiries about doping infringements, which have involved international male athletes who tested positive for the anabolic steroid nandrolone (19-nortestosterone), have raised the important question of whether severe musculoskeletal injury can affect nandrolone metabolism. Both athletes had sustained severe musculoskeletal injury while exercising and were instructed to pass a urine sample for drug testing. Both athletes denied any deliberate illegal doping practice and had never previously failed a drug test. The concentration of 19norandrosterone (19-NA) in the urine of both athlete's ranged from 6-8 ng. $\mathrm{ml}^{-1}$, slightly higher than the International Olympic Committee (IOC) cut-off concentration of 2 ng. $\mathrm{ml}^{-1}$ for male athletes. To our knowledge, no study has yet investigated the possible effect that severe musculoskeletal injury may have on the excretion of nandrolone metabolites (19-NA) and 19moretiocholanolone (19-NE) in the urine of male subjects.

Purpose: The main aim of the study was to validate the International Olympic Committee's cut-off concentration $\left(2 \mathrm{ng} \cdot \mathrm{ml}^{-1}\right)$ for nandrolone metabolites in the urine of male athlete's immediately after severe musculoskeletal injury.

Methods: Descriptive case control study Thirty two $(n=32)$ healthy male subjects between the age of 18 and 50 years, who had sustained severe musculoskeletal injury, were recruited for the study. Blood and urine samples were collected from the subjects within 3 hours of the injury. Blood samples 
were analyzed for plasma cortisol and luteinizing hormone. Urine samples were analyzed for 19-NA and 19-NE and the concentrations reported in pg. $\mathrm{ml}^{-1}$. Baseline urine samples were collected from all subjects six weeks post-injury and analyzed for 19-NA and 19-NE concentrations in the urine.

Results: Urine 19-NA did not change significantly post-injury when compared to baseline $(P=0.70)$. 19-NA levels after injury ranged from $2-2800 \mathrm{pg} \cdot \mathrm{ml}^{-1}$ and at baseline ranged from $0-540 \mathrm{pg} \cdot \mathrm{ml}^{-1}$. Also, urinary $19-\mathrm{NE}$ did not increase significantly post-injury when compared to baseline. Post-injury, 19-NE ranged from 0 $-80 \mathrm{pg} \cdot \mathrm{ml}^{-1}$ and from $0-20 \mathrm{pg} \cdot \mathrm{ml}^{-1}$ at baseline respectively. Exercise and injury in combination did not significantly change 19-NA or 19-NE when compared to those subjects injured but not exercising. One of the subjects, who had not administered synthetic nandrolone, produced a urine 19-NA value of $2800 \mathrm{pg} \cdot \mathrm{ml}^{-1}$, greater than the $10 \mathrm{C}$ cut-off concentration of $2000 \mathrm{pg} \cdot \mathrm{ml}^{-1}$.

Conclusion: This study confirms the endogenous production of small amounts of 19NA and 19-NE in subjects not administering synthetic nandrolone. Musculoskeletal injury did not result in a significant increase in 19-NA and 19-NE concentrations in the urine when compared to baseline. One of the injured subjects, free of synthetic nandrolone, produced a 19-NA concentration of $2800 \mathrm{pg} \cdot \mathrm{ml}^{-1}(\mathrm{IOC}$ cut-off $=2000$ pg. $\mathrm{ml}^{-1}$ ). This suggests that at least 1 in 32 subjects who have a severe musculoskeletal injury will exceed the IOC cut-off concentration for 19-NA (2000 $\left.\mathrm{pg} \cdot \mathrm{ml}^{-1}\right)$. Further research needs to examine the mechanisms causing an increase in 19-NA after musculoskeletal injury so that the $10 \mathrm{C}$ guidelines for a positive nandrolone drug test can be adjusted to reduce the risk of an athlete having a false positive test. 
Furthermore, ethical issues with regards to performing drug testing on athletes after sustaining severe musculoskeletal injury needs to be considered.

Key words: 19-NORANDROSTERONE, 19-NORETIOCHOLANOLONE, MUSCULOSKELETAL INJURY, ADRENAL ANDROGENS, AROMATISATION, INJURY SEVERITY SCORE. 


\subsection{Introduction}

Nandrolone (19-nortestosterone) is an anabolic androgenic steroid currently banned by the International Olympic Committee (IOC). ${ }^{65}$ Exogenous nandrolone administration in athletes is detected by analyzing the urine for the three metabolites of nandrolone namely 19-norandrosterone (19-NA), 19-noretiocholanolone (19-NE) and 19-norepiandrosterone (19-NEA). $5 ; 7 ; 17 ; 59 ; 67 ; 78$ The detection of 19-NA above a urine concentration of $2 \mathrm{ng} \cdot \mathrm{ml}^{-1}$ in male athletes and $5 \mathrm{ng} \cdot \mathrm{ml}^{-1}$ in non-pregnant female athletes is regarded as evidence of exogenous nandrolone administration and constitutes a doping offence according to $10 \mathrm{C}$ doping regulations. ${ }^{65 ; 67}$

Nandrolone in healthy men is undetectable in the plasma $\left(<4 \mathrm{pg} \cdot \mathrm{ml}^{-1}\right),{ }^{5 ; 73}$ however, recent scientific evidence has confirmed that small amounts of nandrolone metabolites can be detected in the urine of humans who have not administered exogenous nandrolone. ${ }^{10 ; 20 ; 28 ; 43 ; 48: 51 ; 72 ; 75 ; 79 ; 93}$ Therefore, it may be concluded that small amounts of nandrolone are produced endogenously in the human body. The precise endocrine pathway for endogenous nandrolone production has yet to be established. However, animal studies, in vitro experiments and research from humans, particularly pregnant woman, add support to the proposal that 19-norsteroids are intermediates in the aromatisation of androgens to estrogen. 7;10;20;21;40;62;72;73;86;90;93 This metabolic pathway has the potential to be upregulated, as demonstrated by the increase in the concentration of 19-NA in the urine of humans after the administration of human chorionic gonadotropin. ${ }^{72}$ This important finding raises the possibility that other factors may alter the production and excretion of nandrolone metabolites in the urine of humans. 
Anecdotal evidence presented at two recent doping infringement enquiries raised the possibility of an interaction between musculoskeletal injury and the concentration of 19-NA in the urine of humans. Two international male athletes tested positive for nandrolone when the concentration of 19-NA in their urine exceeded $2 \mathrm{ng} \cdot \mathrm{ml}^{-1}$. Both athletes had sustained significant musculoskeletal injuries immediately prior to passing a urine sample for drug testing. One athlete was an international rugby player, who sustained a wrist bone fracture ${ }^{64}$. The other athlete was a ParaOlympian wheelchair sprinter (Personal communication), who dislocated his shoulder while overreaching for the finish line. The concentration of 19-NA in the urine samples of both athletes was approximately $6-8 \mathrm{ng} \cdot \mathrm{ml}^{-1}$, which is slightly above the $10 \mathrm{C}$ cut-off concentration for men (2 ng. $\left.\mathrm{ml}^{-1}\right)$. Both athletes denied having ever used any nandrolone containing products previously.

To date, no study has investigated the possible effect of musculoskeletal injury on the excretion of nandrolone metabolites in the urine of male subjects. Accordingly, the aim of this study was to determine if musculoskeletal injury in male subjects could increase the concentration of nandrolone metabolites (19-NA and 19-NE) in the urine.

\subsection{Methods}

\section{Study design}

A case-control study was conducted in the Accident and Emergency Unit of Milnerton Medi-Clinic, South Africa, following ethical approval by the Ethics and Research Committee of the Faculty of Health Sciences, University of Cape Town, South Africa. 


\section{Subjects}

Thirty two $(n=32)$ male subjects admitted to the Milnerton Medi-Clinic Accident and Emergency Unit with severe musculoskeletal injuries were recruited for the study. The exclusion criteria were strictly applied (Appendix D). The subjects were all physically active, competing on a recreational level and denied any current or previous anabolic steroid use. The descriptive characteristics of the subjects are shown in Table 3.1. The average age of the subjects was $30.8 \pm 7.6$ years (range $18-43$ years). The average values for body mass, stature and body mass index are $82.3 \pm 16.6 \mathrm{~kg}$, $176.1 \pm 16.6 \mathrm{~cm}$ and $26.5 \pm 5.0 \mathrm{~kg} \cdot \mathrm{m}^{-2}$ respectively. All subjects performed regular weekly exercise activity, training on average $242 \pm 161$ min.week $^{-1}$ (range $60-720$ min.week ${ }^{-1}$ ) and fulfilled the inclusion criteria for being moderately active individuals.

Table 3.1 Descriptive characteristics of the subjects $(n=32)$.

\begin{tabular}{lccc}
\hline $\mathbf{N}=32$ & Mean $\pm \mathrm{SD}$ & Minimum & Maximum \\
\hline Age (years) & $30.8 \pm 7.6$ & 18.0 & 43.0 \\
Body mass $(\mathrm{kg})$ & $82.3 \pm 16.6$ & 50.0 & 125.0 \\
Stature $(\mathrm{cm})$ & $176.1 \pm 16.6$ & 154.0 & 196.0 \\
BMI $\left(\mathrm{kg}_{\mathrm{m}} \mathrm{m}^{-2}\right)$ & $26.5 \pm 5.0$ & 19.8 & 41.3 \\
Training time $\left(\right.$ min. $\left.\mathrm{wk}^{-1}\right)$ & $242 \pm 161$ & 60 & 720 \\
\hline
\end{tabular}

All subjects required treatment for a musculoskeletal injury and presented to the emergency unit for treatment within 3 hours of sustaining the injury. A medical history and examination were performed. If a bone fracture, joint dislocation or tendon rupture was suspected clinically and less than 3 hours had elapsed, the subject was asked to participate in the study. Subjects gave written informed consent after the study protocol had been fully explained to them. The time of the injury was 
documented. A blood sample to measure plasma cortisol and luteinizing hormone and a urine sample to measure 19-NA and 19-NE concentrations were collected from all the subjects. The time of blood and urine sample collection was documented. Analgesia was administered after the collection of urine and blood samples. ${ }^{85}$ X-rays were performed to confirm the diagnosis. After the $X$-ray, subjects were assigned an Injury Severity Score (ISS). ${ }^{2}$ To calculate the ISS, the injury was graded as minor $=1$, moderate $=2$, severe but not life threatening $=3$, severe life threatening $=4$ or critical $=5$. If one injury was present, the score that was allocated for that injury is squared. If two injuries were present, the score for each injury was squared and both scores added together. ${ }^{2}$ Based on the criteria for this study, an ISS for a single bone fracture, joint dislocation or tendon rupture ranged from an ISS score of 4-9. Subjects with an ISS of 4-13 were eligible for the study. Subjects completed questionnaires to document demographic details and a training history. All subjects received standard appropriate medical treatment for their respective injury. The treatment was not altered by their participation in the study. Six weeks after the injury, a baseline urine sample was collected from the subjects $(n=32)$ for the measurement of 19-NA and 19NE concentrations. No blood samples were collected six weeks after the injury.

\section{Blood sampling and analytical procedure}

Blood samples $(5 \mathrm{ml})$ were collected using strict aseptic technique from the right antecubital vein of each of the subjects $(n=32)$ and placed into SSTB Gel and Clot Activator vacutainers (Preanalytical Systems, Plymouth, UK). Immediately after collection, the blood was centrifuged at $3000 \times \mathrm{g}$ for ten minutes. Plasma cortisol and leutinizing hormone (LH) were assayed using a competitive immunoassay with chemiluminescent technology (Advia Centaur, Bayer Corporation, Tarrytown, NY, 
USA). Plasma cortisol was quantified in $n m o l . L^{-1}$ and $L H$ results were quantified in IU.L-1.

Urine sample collection and transportation

Urine samples were collected within 3 hours of sustaining a musculoskeletal injury. Urine specific gravity (SG), urine $\mathrm{pH}$ and urine creatinine were measured as approximate indicators of the subject's hydration status. Urine aliquots $(40 \mathrm{ml})$ were stored at $-20^{\circ} \mathrm{C}$. Although it is recommended that urine be stored under these conditions, a recent research study has shown that different storage conditions do not significantly alter the concentration of nandrolone metabolites in the urine. ${ }^{92}$ The samples were couriered by DHL Express to Hall Analytical Laboratories in Manchester, United Kingdom. The cold chain was maintained throughout the transportation.

Urine 19-NA and 19-NE steroid analysis

At Hall Analytical Laboratories (Manchester, United Kingdom), all samples were stored in a freezer at $-80^{\circ} \mathrm{C}$. Before analysis, each sample was removed from the freezer and allowed to thaw at room temperature for 60 minutes. Ten $\mathrm{ml}$ of urine were decanted from each sample and placed into individual $50 \mathrm{ml}$ glass sample vials. Any excess urine was returned to the freezer $\left(-80^{\circ} \mathrm{C}\right)$.

Steroid extraction and purification

Before steroid extraction and purification, $10 \mathrm{ng}$ of testosterone- $\mathrm{d}_{3}$ (Sigma standard T5536, Steinheim, Germany) was added to the urine as an internal standard. The steroid content of the sample was hydrolyzed with $0.5 \mathrm{ml}$ (minimum $50 \mathrm{IU}$ ) of $\mathrm{E}$. Coli $\beta$ - 
glucuronidase (Sigma g-8396) for 60 minutes at $52^{\circ} \mathrm{C}$ (buffered at $\mathrm{pH} 6.8$ ). The hydrolyzed sample was applied to a pre-conditioned C-18 cartridge (Supelco DSC-18 $6 \mathrm{~m}$ l tubes, 52606-U, Sigma-Aldrich Co. 2001, Bellefonte, USA), which was then flushed with $6 \mathrm{ml}$ of de-ionized water and $6 \mathrm{ml}$ of hexane. The sample was then eluted from the column by flushing with $6 \mathrm{ml}$ of methanol. Once eluted, the extract was dried under a constant flow of nitrogen at a temperature of $40^{\circ} \mathrm{C}$.

The dried residue was diluted in $500 \mu$ l of hexane / dichloromethane $(60: 40 \mathrm{~V} / \mathrm{V})$ and placed in an ultrasonic bath for 30 minutes. The extract was then applied to a preconditioned DSC-Si silica tube (Supelco DSC-Si $6 \mathrm{ml}$ tubes, 52656-U, SigmaAldrich Co. 2001, Bellefonte, USA). This procedure was carried out under low flow rates with $10 \mathrm{ml}$ of hexane. Following sample application, the colurnn was allowed to dry for 3 minutes and then flushed with $8 \mathrm{~m}$ of hexane / ethylacetate $(85: 15 \mathrm{v} / \mathrm{v})$. The sample was eluted with $13 \mathrm{ml}$ of hexane and ethylacetate $(60: 40 \mathrm{v} / \mathrm{v})$ and the resultant solution blown to dryness under a constant stream of nitrogen at $40^{\circ} \mathrm{C}$.

\section{Derivitization}

The dry residue was derivatized with $\mathrm{N}$-Methyl-N-(trimethylsilyl) trifluoroacetamide (MSTFA, Sigma 39,486-6, ) and N-Trimethylsilylimidazole (TMSI, Sigma 39,487-4 Steinheim, Germany) (100:3 v/v) at $50{ }^{\circ} \mathrm{C}$ for 120 minutes to form Trimethylsilyl-enoltrimethylsilyl - ethers.

\section{GC-MS analysis}

Analysis was performed on a Micromass Autospec high-resolution mass spectrometer (Micromass UK Ltd, Manchester, UK) coupled to a Hewlett-Packard 5890 Gas Chromatograph (Palo Alto, CA, USA). A DB-5 MS $30 \mathrm{~m}$ column, with a film thickness 
of $0.25 \mu \mathrm{m}$, was used to achieve chromatographic separation. The GC was run in splitless mode, with an injection temperature of $280^{\circ} \mathrm{C}$ and a constant pressure of 70 $\mathrm{kPa}$. The temperature of the oven was set initially to $80^{\circ} \mathrm{C}$ for 2 minutes, and increased at $10^{\circ} \mathrm{C}$ per minute to $200^{\circ} \mathrm{C}$. The rate of temperature increase was then decreased to $4^{\circ} \mathrm{C}$ per minute until a final temperature of $315^{\circ} \mathrm{C}$ was reached, the $\mathrm{GC}$ oven was then held constant at this temperature for a further 15 minutes.

The mass spectrometer was run at a resolution of $5000 \mathrm{~Hz}(10 \%$ valley definition) whilst monitoring ions with an $\mathrm{m} / \mathrm{z}$ ratio of 435,420 and 405 . To improve the resolution of the system the less abundant ions $(\mathrm{m} / \mathrm{z} 215$ and 315$)$ were not monitored although their presence had been determined prior to high-resolution analysis. Heptacosa ( $\mathrm{m} / \mathrm{z} 414)$ was used as the lock mass. A $1 \mu$ injection of sample proved sufficient for peak detection and quantification to produce above average chromatographic and mass spectrum data for unambiguous identification of 19-NA and 19-NE. A typical spectrograph mass chromatogram obtained by this method can be seen in Figure $3.1 \mathrm{a}, \mathrm{b}, \mathrm{c}$.

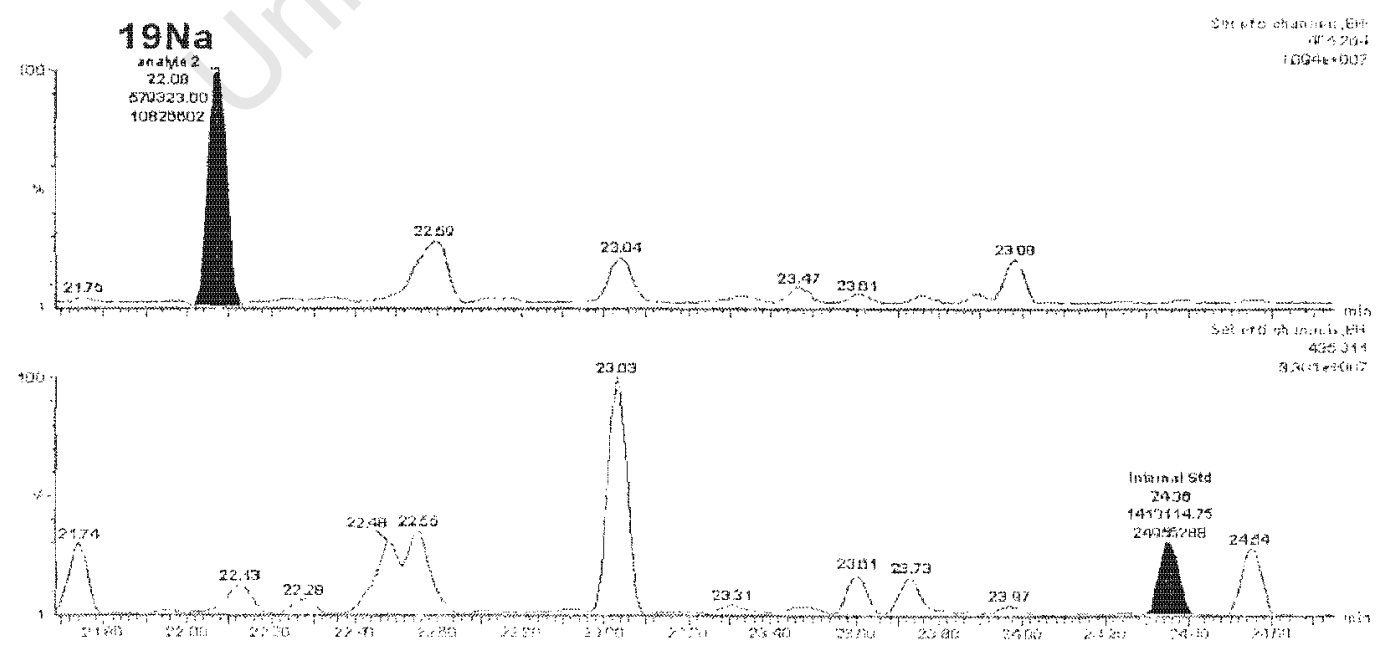


Figure 3.1a Single ion monitoring spectrograph mass chromatogram $(\mathrm{m} / \mathrm{z} 405)$ of the 19-NA and 19-NE content of an athlete's urine following acute musculoskeletal injury.

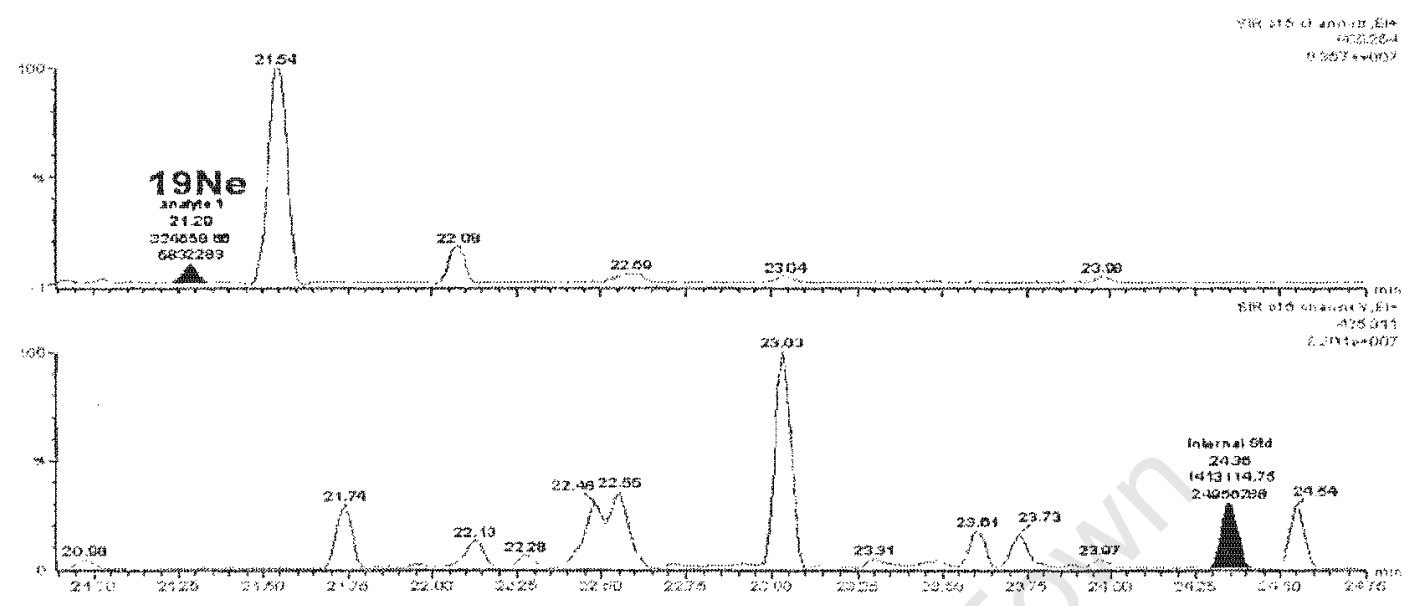

Figure 3.1b Single ion monitoring mass chromatogram $(\mathrm{m} / \mathrm{z} 405)$ of the $19-\mathrm{NE}$ content of an athlete's urine following acute musculoskeletal injury.

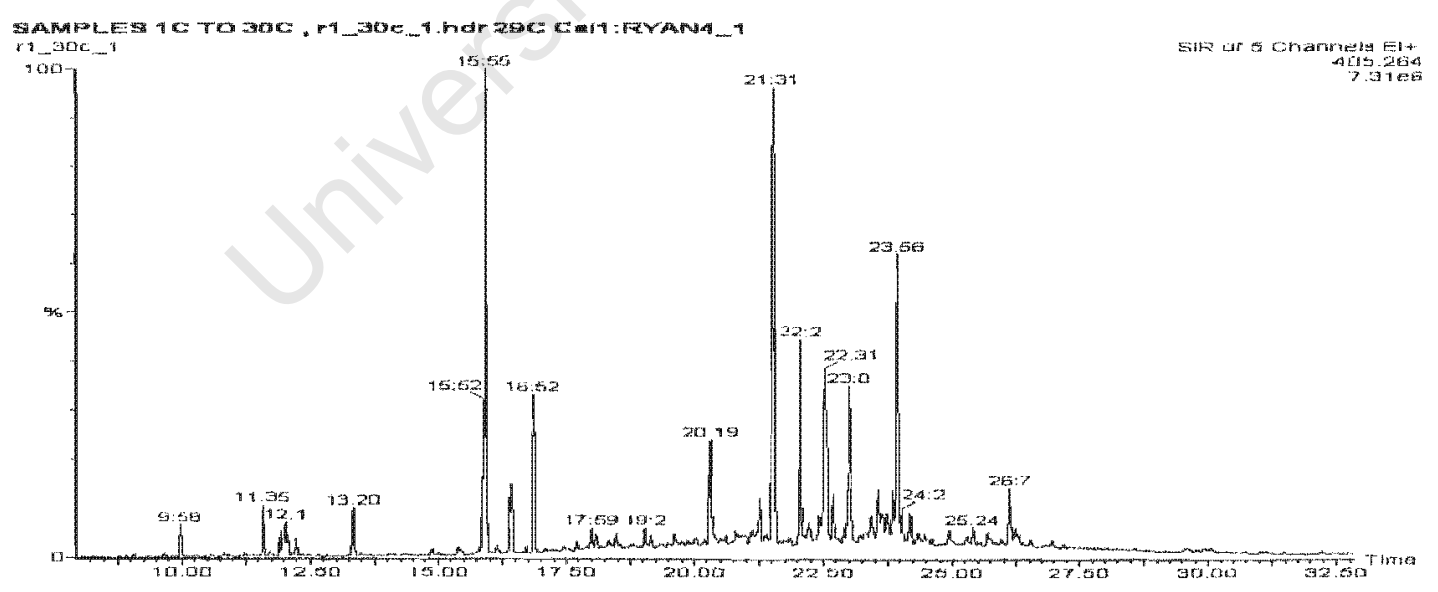

Figure 3.1c. Single ion monitoring spectrograph $(\mathrm{m} / \mathrm{z} 405)$ of the 19-NA and 19-NE content of an athlete's urine following acute musculoskeletal injury. 


\section{Quantification}

Calibration was carried out using 19-NA and 19-NE standards purchased from Steraloids (Wilton, NH, USA). Following the injection of $10 \mathrm{ng}$ of testosterone- $\mathrm{d}_{3}$, the standards were derivatized and analyzed in the same manner as the samples (as described above). The calibration curve consisted of seven points distributed from 1 to $5000 \mathrm{pg} . \mathrm{ml}^{-1}$ producing a linear line of best fit with an $r^{2}$ of $\geq 0.98$. The detection limit of the Autospec was $<10 \mathrm{pg} \cdot \mathrm{ml}^{-1}$ for $19-\mathrm{NA}$ and $19-\mathrm{NE}$. As such $1 \mathrm{pg} \cdot \mathrm{ml}^{-1}$ was taken as the limit of accurate analysis. Analytical recovery was greater than $90 \%$. The 19-NA and 19-NE concentrations are expressed in pg: $\mathrm{ml}^{-1}$. To convert to the units reported by the $10 \mathrm{C}\left(\mathrm{ng} \cdot \mathrm{ml}^{-1}\right)$, divide $\mathrm{pg} \cdot \mathrm{ml}^{-1}$ by 1000 .

\section{Statistical analysis}

All values are presented as the mean \pm standard deviation (mean \pm SD). Statistical analyses were performed using the Statistica software version 6.1 (Statsoft, Inc, Tulsa, OK, USA). Data were analysed using the dependent $t$ test to compare samples collected at post-injury and at baseline. Where data showed significant variance and skewness in distribution and did not fulfill the criteria for normally distributed parametric data, the Wilcoxon Matched Pairs test was used to determine differences. Pearson's Product Moment Correlation was used to establish the relationship between variables. A Spearman's Rank Order Correlation was used to establish a relationship between the ISS score and the other variables. Statistical significance was accepted as $\mathrm{P}<0.05$ 


\subsection{Results}

Irjury characteristics of the subjects

The injury characteristics of the subjects are shown in Table 3.2. Twenty six subjects sustained a bone fracture $(81 \%)$, four subjects sustained a joint dislocation (13\%) and two subjects sustained an Achilles tendon rupture (6\%). The injury severity score ranged from 4-12 arbitrary units, fulfilling the criteria in the study for a moderate to severe injury.

Table 3.2 Descriptive characteristics of the injuries $(n=32)$.

\begin{tabular}{lccc} 
& Injury type 1" & Injury type $2^{*}$ & Injury type $3^{\phi}$ \\
\hline Number of subjects & $26(81 \%)$ & $4(13 \%)$ & $2(6 \%)$ \\
$\begin{array}{l}\text { Injury severity } \\
\text { score (arbitrary } \\
\text { units) }\end{array}$ & $9 \pm 3$ & $9 \pm 0$ & $9 \pm 0$ \\
\hline "injury type 1 = bone fracture * injury type $2=$ joint dislocation ${ }^{\phi}$ injury type $3=$ tendon rupture
\end{tabular}

The data describing the time of the musculoskeletal injury and the time of urine sample collection are shown in Table 3.3. The majority of injuries occurred just after midday ( $13 \mathrm{~h} 28 \mathrm{~min} \pm 3 \mathrm{~h} 04 \mathrm{~min}$ ), with the earliest injury occurring at $04 \mathrm{~h} 00 \mathrm{~min}$ in the morning and the latest injury occurring at $18 \mathrm{~h} 00 \mathrm{~min}$ in the evening. All urine samples were collected within the prescribed 3 hour cut-off period after injury (1h 16 min \pm oh $40 \mathrm{~min}$ ) as defined for the study protocol. The earliest urine sample was collected within 25 minutes of the injury occurring and the latest urine sample was collected 3 hours after the injury. 
Table 3.3 The time of the musculoskeletal injury and urine sample collection in the subjects.

Mean \pm SD Minimum Maximum

$\begin{array}{lccc}\text { Time of injury (h:min) } & 13 \mathrm{~h} 28 \mathrm{~min} \pm 3 \mathrm{~h} \mathrm{04} \mathrm{min} & 04 \mathrm{~h} \mathrm{00} \mathrm{min} & 18 \mathrm{~h} \mathrm{00} \mathrm{min} \\ \text { Time of urine collection } & 14 \mathrm{~h} 44 \mathrm{~min} \pm 2 \mathrm{~h} 58 \mathrm{~min} & 07 \mathrm{~h} \mathrm{00} \mathrm{min} & 19 \mathrm{~h} 19 \mathrm{~min} \\ \Delta \text { time between injury } & 1 \mathrm{~h} 16 \mathrm{~min} \pm \text { oh } 40 \mathrm{~min} & \text { oh } 25 \mathrm{~min} & 3 \mathrm{~h} \mathrm{00} \mathrm{min} \\ \text { and urine collection } & & & \end{array}$

Plasma hormone concentrations

The plasma hormone concentrations of the subjects post-injury are shown in Table 3.4. The average plasma cortisol was $739 \pm 316 \mathrm{nmol} . \mathrm{L}^{-1}$ and varied widely from 326 to 1564 nmol.L $\mathrm{L}^{-1}$ post-injury (Figure 3.2). The plasma cortisol values represent a significant stress response to the musculoskeletal injury compared to basal diurnal plasma cortisol concentrations reported as ranging from 85 to $620 \mathrm{nmol} . \mathrm{L}^{-1}$ (Pathcare Laboratories, South Africa) (Figure 3.3). All the plasma LH concentrations were within the normal physiological range $\left(1.0-15.01 U . \mathrm{L}^{-1}\right)($ Pathcare Laboratories, South Africa). The average plasma LH was $5.6 \pm 3.4$ IU.L. ${ }^{-1}$ and varied widely from 1.1 to 12.7 IU.L $L^{-1}$ (Figure 3.4 )

Table 3.4 Plasma cortisol and LH responses in male subjects post-injury $(n=32)$.

\begin{tabular}{lccc} 
& Mean $\pm \mathrm{SD}$ & Minimum & Maximum \\
& & & \\
\hline Plasma cortisol (nmol.L-1 $)$ & $739 \pm 316$ & 326 & 1564 \\
Plasma LH (IU.L & & 1.1 & 12.7 \\
\hline
\end{tabular}




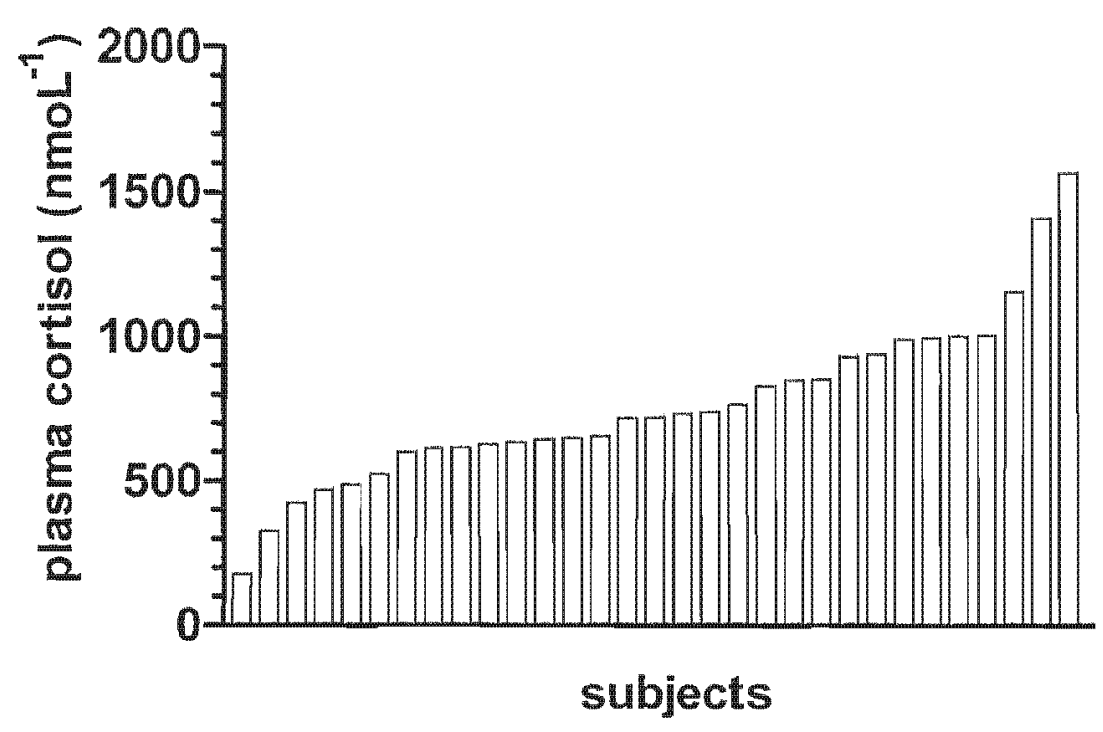

Figure 3.2 Inter-individual variation in plasma cortisol concentrations post-injury.

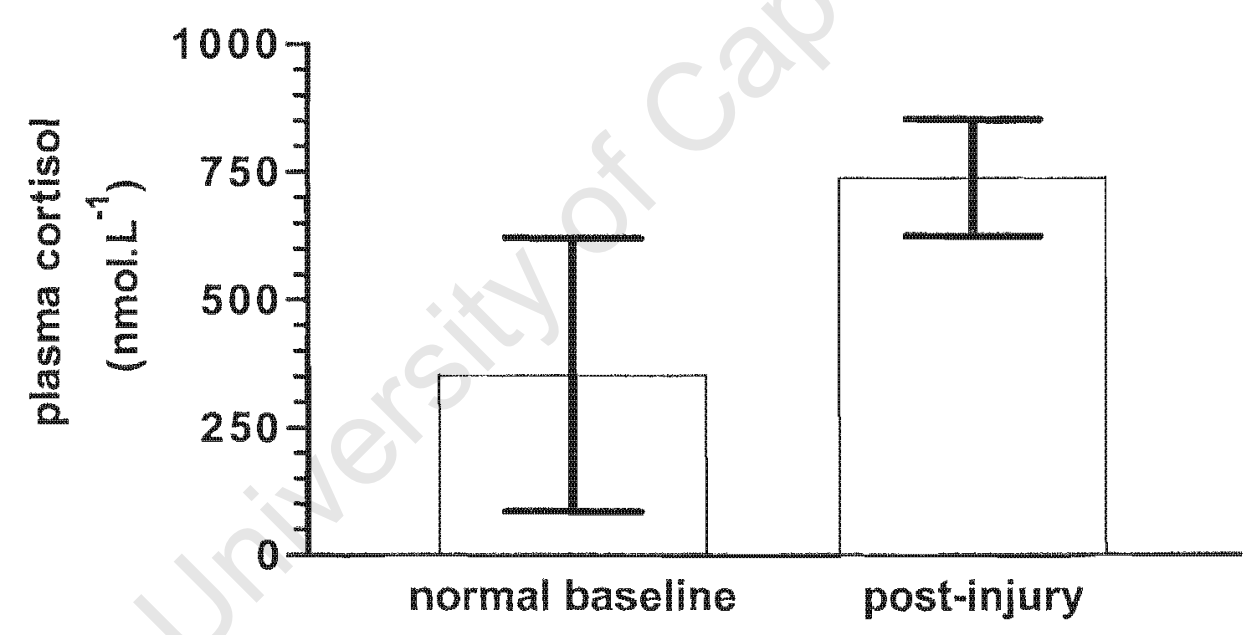

Figure 3.3 Plasma cortisol concentrations (mean $\pm \mathrm{SD}$ ) post-injury are compared to normal baseline. 


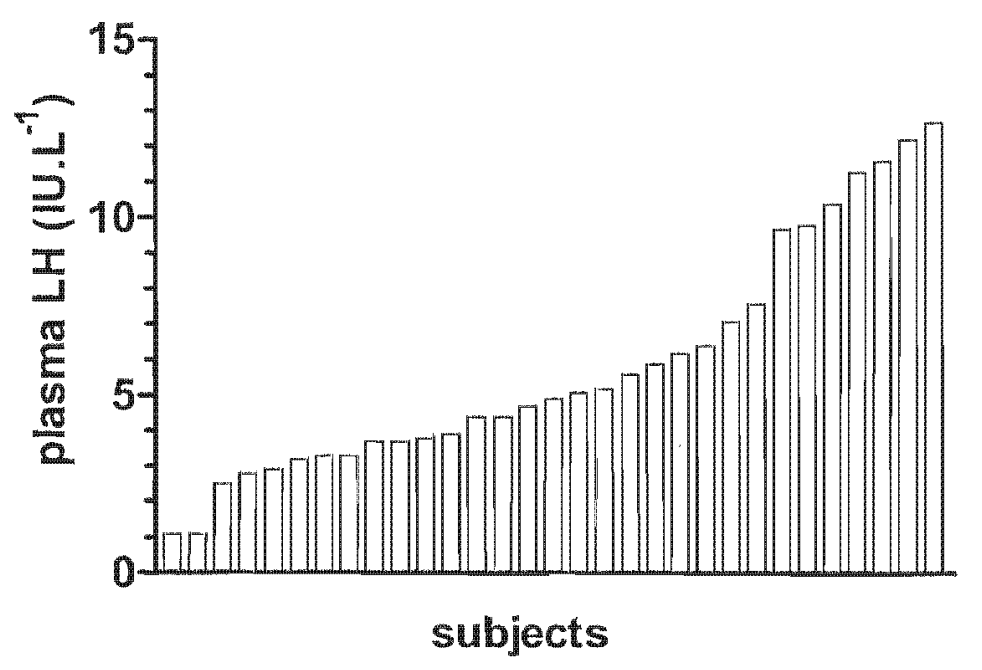

Figure 3.4 Inter-individual variation in plasma LH concentrations post-injury.

\section{Urinary characteristics}

The urine characteristics of the subjects are shown in Table 3.5. Urine creatinine, SG and $\mathrm{pH}$ were all within the normal range and therefore unlikely to affect the analysis of the urine samples for nandrolone metabolite concentrations.

Table 3.5 Urine characteristics in male subjects after sustaining musculoskeletal injury $(n=32)$.

\begin{tabular}{lccc}
\hline Variable & Mean \pm SD & Minimum & Maximum \\
\hline $\begin{array}{l}\text { Urine creatinine } \\
\left.\text { (mmol. } L^{-1}\right)\end{array}$ & $19.7 \pm 8.1$ & 4.5 & 36.1 \\
Urine SG & $1.024 \pm 0.007$ & 1.010 & 1.030 \\
Urine $\mathrm{pH}$ & $5.9 \pm 0.6$ & 5.0 & 7.5 \\
\hline
\end{tabular}

Urinary 19-NA and 19-NE concentrations

The urine 19-NA and 19-NE concentrations of the subjects post-injury and at baseline are shown in Table 3.6. 19-NA at baseline was $140 \pm 130 \mathrm{pg} \cdot \mathrm{ml}^{-1}$ and ranged from 
undetectable levels to $540 \mathrm{pg} \cdot \mathrm{ml}^{-1}$ (Figure 3.5 (a)). 19-NA post-injury averaged $169 \pm$ $488 \mathrm{pg} \cdot \mathrm{ml}^{-1}$. There was a wide individual variation ranging from $2-2800 \mathrm{pg} \cdot \mathrm{ml}^{-1}$ (Figure 3.5 (b)). There was no significant difference between 19-NA in the urine postinjury when compared to baseline $(P=0.7)$ (Figure 3.6(a)). There was a significant increase in 19-NE post-injury compared to baseline $(\mathrm{P}<0.05)$ (Figure 3.6(b)). 19-NE at baseline averaged $6 \pm 5 \mathrm{pg} \cdot \mathrm{ml}^{-1}$, ranging from undetectable levels to $20 \mathrm{pg} \cdot \mathrm{ml}^{-1}$ (Figure 3.7(a)). 19-NE post-injury was $13 \pm 19 \mathrm{pg} \cdot \mathrm{ml}^{-1}$, ranging from undetectable levels to $80 \mathrm{pg} \cdot \mathrm{ml}^{-1}$ (Figure $3.7(\mathrm{~b})$ ). If the subject with the high level of 19-NA and 19NE is excluded on the basis of being an outlier, then the difference in 19-NE was not significant $(P=0.08$ dependant $t$ test $)$. Similarly, if the data are analyzed with a Wilcoxon Matched Pairs test for non-parametric data, the 19-NE values are not significantly different (post-injury vs baseline) $(P=0.1)$

Table 3.6 Urinary 19-NA and 19-NE concentrations immediately post-injury and at baseline.

\section{Post-injury Baseline}

$\begin{array}{ccc}\text { Urine 19-NA }\left(\mathrm{pg} \cdot \mathrm{ml}^{-1}\right) & 169 \pm 488 & 140 \pm 130 \\ \text { Urine 19-NE }\left(\mathrm{pg} \cdot \mathrm{ml}^{-1}\right) & 13 \pm 19 & 6 \pm 5\end{array}$




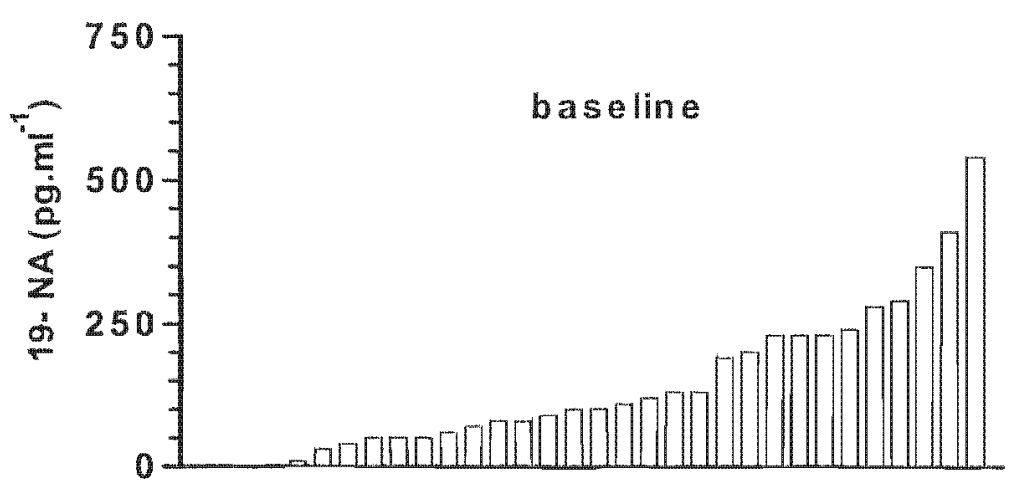

(a)

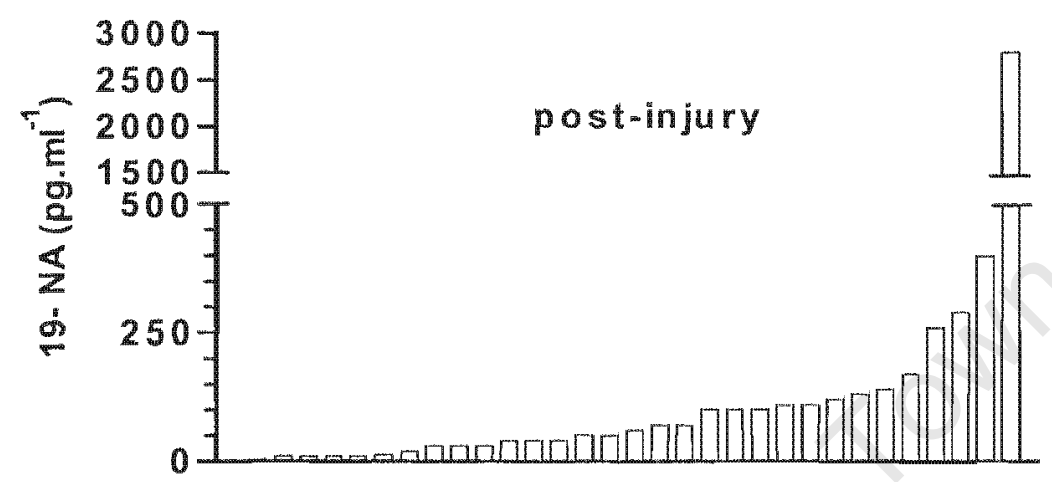

(b)

Figure 3.5 (a) and (b) Inter-individual variation in urinary 19-NA concentrations at baseline (a) and post-injury (b).

19-NE
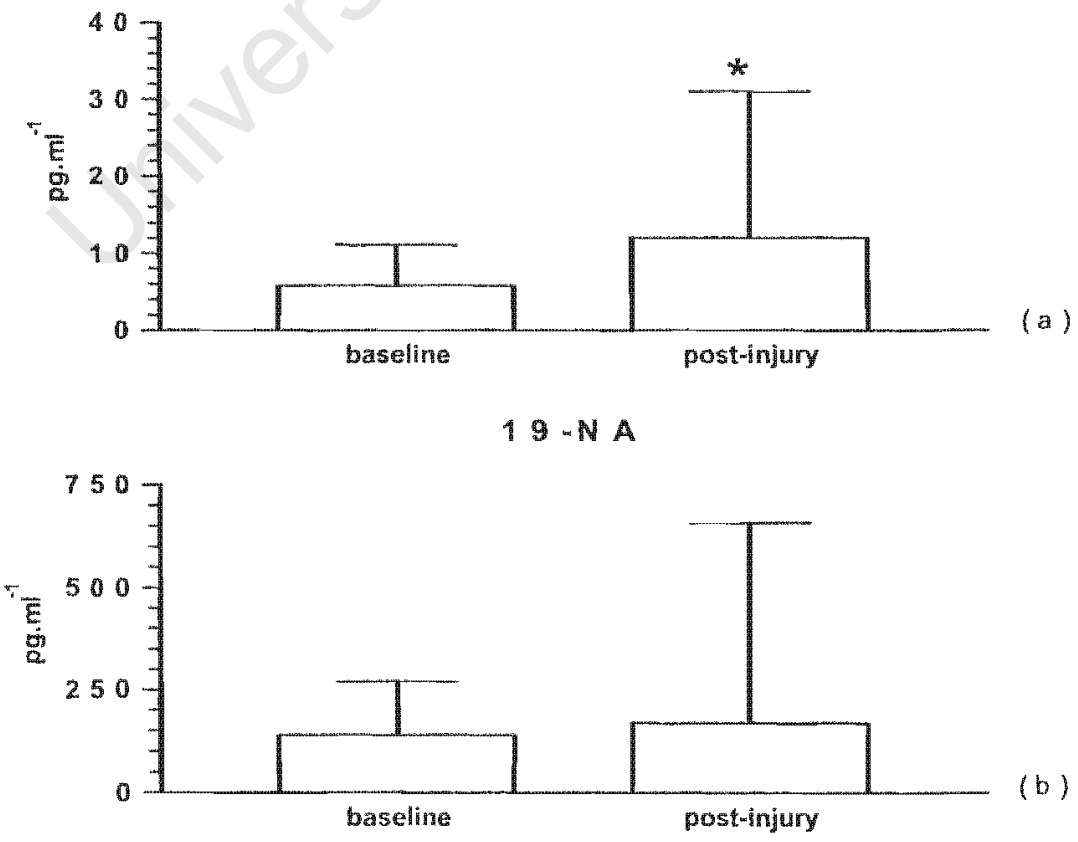
Figure 3.6 (a) and (b) Urine 19-NE (pg. $\left.\mathrm{ml}^{-1}\right)$ post-injury and at baseline (a) and urine 19-NA (pg. $\left.\mathrm{m}^{-1}\right)$ post-injury and at baseline $(b)(n=32)$. $* P<0.05$ (all data included).
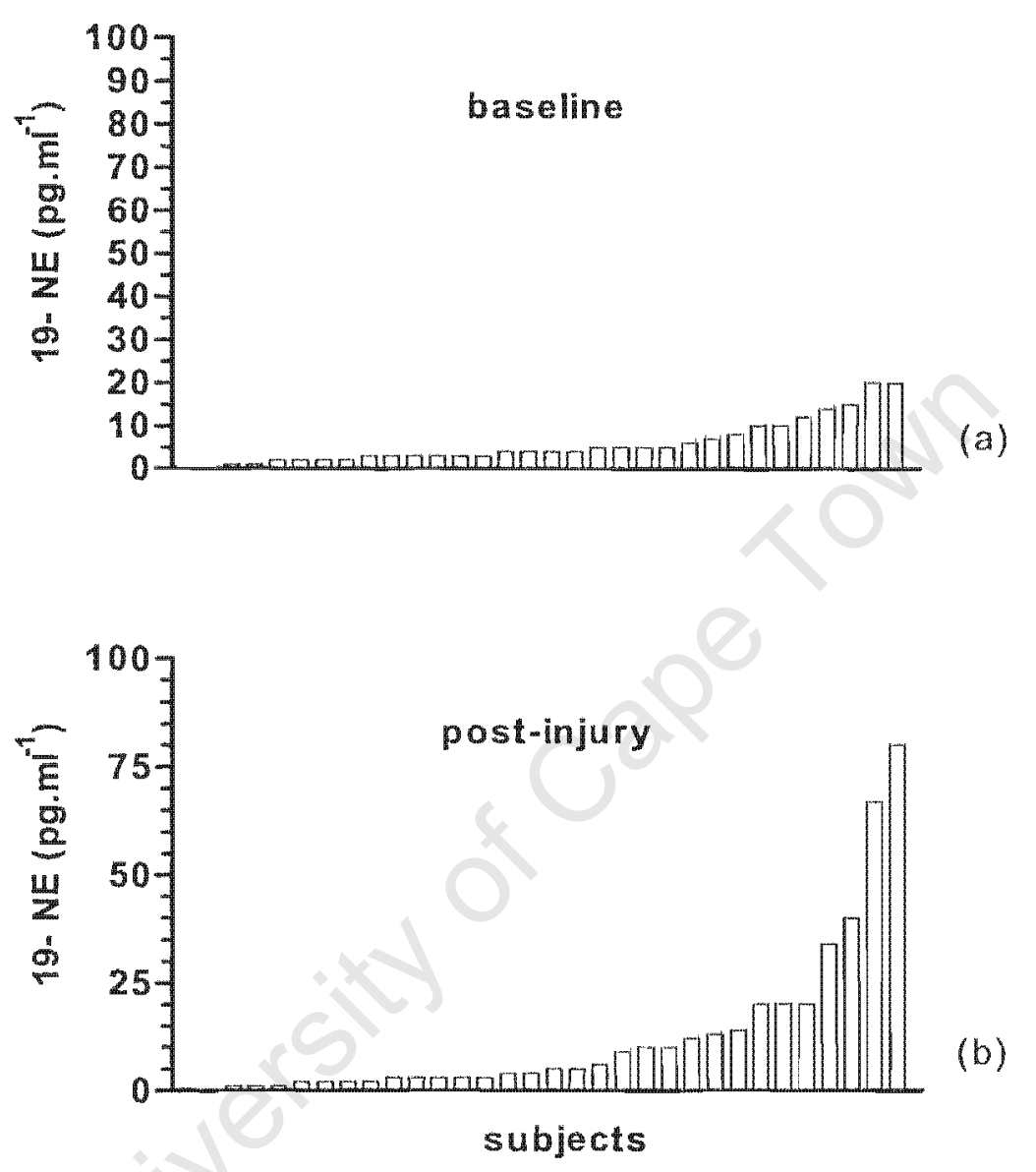

Figure 3.7 (a) and (b) Inter-individual variation in urinary 19-NE concentrations at baseline (a) and post-injury (b).

There was no significant relationship between the body mass index of the subjects and urinary 19-NA $(P=0.59)$ and 19-NE $(P=0.29)$ post-injury. Also, there was no significant relationship between plasma cortisol post-injury and ISS $(P=0.36)$. Urine $\mathrm{pH}$, urine SG and urine creatinine were not significantly related to urinary 19-NA and 
19-NE both post-injury and at baseline. Further, training time per week was not related to urinary 19-NA $(P=0.73)$ and $19-N E(P=0.63)$ after the injury.

The subjects in the study were further subdivided into 2 sub-groups. Sub-group A sustained musculoskeletal injury while performing exercise $(n=20)$ and Sub-group B sustained musculoskeletal injury while at rest $(n=12)$ (Table 3.7). Both groups showed a similar increase in cortisol concentrations post-injury and hence showed a similar stress response, with no significant difference between the sub-groups (743.8 \pm 326.3 vs $731.7 \pm 313.0$; exercise vs rest; $P=0.09$ ). There was no significant difference between subgroups in urinary 19-NA post-injury $(P=0.28)$ and at baseline $(P=0.86)$. Similarly, there was no significant difference in urinary 19-NE post-injury $(P=0.43)$ and at baseline $(P=0.47)$ between the sub-groups.

Table 3.7 Urinary 19-NA and 19-NE concentrations for Sub-group $A(n=20)$ and Subgroup $B(n=12)$.

\begin{tabular}{lcccc}
\hline & \multicolumn{2}{c}{ post-injury } & \multicolumn{2}{c}{ baseline } \\
\hline & $19-\mathrm{NA}\left(\mathrm{pg} \cdot \mathrm{ml}^{-1}\right)$ & $19-\mathrm{NE}\left(\mathrm{pg} \cdot \mathrm{ml}^{-1}\right)$ & $19-\mathrm{NA}\left(\mathrm{pg} \cdot \mathrm{ml}^{-1}\right)$ & $19-\mathrm{NE}\left(\mathrm{pg} \cdot \mathrm{ml}^{-1}\right)$ \\
\hline Sub-group A & $95.9 \pm 98.1$ & $14.6 \pm 22.5$ & $137.2 \pm 129.5$ & $6.4 \pm 5.9$ \\
Sub-group B & $291.7 \pm 793.4$ & $9.0 \pm 9.6$ & $145.8 \pm 137.2$ & $4.9 \pm 4.1$ \\
P-value & 0.28 & 0.43 & 0.86 & 0.47 \\
\hline
\end{tabular}

Sub-group A: Performing exercise when sustaining musculoskeletal injury; Sub-group $B$ : At rest when sustaining musculoskeletal injury. 


\subsection{Discussion}

The main finding in this study was that one of the subjects, who had not reportedly administered exogenous nandrolone and who did not consume any nutritional supplements, produced a urine 19-NA concentration post-injury which exceeded the $10 \mathrm{C}$ cut-off concentration of $2000 \mathrm{pg} \cdot \mathrm{ml}^{-165 ; 67}$. This finding represents a false positive result for a nandrolone drug test. This may represent a one in thirty two chance of an individual producing 19-NA in the urine above the $10 \mathrm{C}$ cut-off concentration after severe musculoskeletal injury. It is not known how often athletes who have sustained severe musculoskeletal injury are instructed to pass urine for drug testing, however this finding would suggest that a false positive finding after sustaining musculoskeletal injury may not be an uncommon finding. There was a wide variation in the 19-NA concentration in the urine of the subjects and this value $\left(2800 \mathrm{pg} \cdot \mathrm{ml}^{-1}\right)$ does represent a significant outlier. The result warrants a comprehensive endocrinological investigation and the simulation of a further stress response to determine if this result is reproducible in this subject.

Secondly, musculoskeletal injury did not consistently increase the concentration of 19NA in the urine of subjects post-injury when compared to baseline. There was a tendency for the urine concentration of 19-NE to increase post-injury when compared to baseline. However, the data lacked statistical power making it difficult to show significant difference. The data were biased as one of the subjects had unusually elevated 19-NA and 19-NE concentrations post-injury. If this subject was excluded from the analysis on the basis of being an outlier, then it becomes apparent that the concentration of 19-NA in the urine tends to be lower post-injury when compared to baseline, although not statistically significant. 
This is the first study in humans which has investigated the possible effect that a severe physiological stress may have on the excretion of nandrolone metabolites (19NA and 19-NE) in the urine. The question became apparent after two elite male athletes tested positive for nandrolone after sustaining severe musculoskeletal injury.\{41\} Also, Reznik et al. ${ }^{72}$ has shown that the excretion of 19-NA in the urine may show an upward trend within 2 hours of a physiological hypoglycaemic stress response. This finding was however not significant, possibly because of the low statistical power as a result of the small sample size $(n=10) .^{72}$

All subjects in the present study had normal plasma LH concentrations, indicative of normal function of the hypothalamic-pituitary axis. This suggests indirectly that exogenous androgenic anabolic steroids had not been administered as androgenic anabolic steroids may suppress the hypothalamic-pituitary axis and attenuate LH secretion. ${ }^{56 ; 88}$ Additionally, plasma cortisol concentrations increased significantly postinjury, in accordance with a physiological stress response. ${ }^{81}$ The rapid increase in cortisol is mediated by ACTH which increases immediately after injury. ${ }^{81}$ Within 2 hours of moderate to severe injury (ISS $<13$ ), plasma cortisol and ACTH increase in parallel. $^{4}$ Therefore, blood samples were collected within 3 hours of injury in an attempt to ensure that the adrenal cortex was being maximally stimulated by $A C T H$. All subjects were not shocked and perfusing all organs normally. Plasma cortisol measured after injury is not influenced by diurnal variation ${ }^{4}$ and therefore the timing of blood sampling did not have to be standardized in this study. ACTH acts as the sole stimulus of the adrenal cortex resulting in the excretion of adrenal androgens, glucocorticoids and mineralocorticoids. ${ }^{4 ; 29}$ In planning this study it was hypothesized that during a physiological stress the adrenal cortex could be a source of andrenal 
androgens and therefore increase the excretion of aromatisation intermediates. In this study, the adrenal cortex would have been maximally stimulated post-injury and if adrenal androgens were increased, then it is feasible that they would have increased the excretion of 19-NA and 19-NE. There is evidence to show that the dog adrenal gland has the aromatase enzyme ${ }^{66}$. However, in porcine and human adrenal glands, the aromatase enzyme complex may not be present ${ }^{12 ; 97}$ Therefore it is unlikely that any increase in adrenal androgens would be aromatized, possibly explaining why $19-$ NA and 19-NE did not increase consistently in this study. The findings of our study would seem to support the above, although adrenal androgens were not measured.

In healthy individuals, testicular androgens have been shown to decrease during a physiological stress response ${ }^{24 ; 72}$ due to cortisol binding to Leydig cell receptors, down-regulation of $L H$ receptors or a centrally-mediated inhibition of $L H$ secretion. 3;25;69;74 The decrease in the androgen concentrations could therefore result in a decrease in the urinary excretion of 19-NA and 19-NE. This did not occur so the proposed mechanism needs to be re-evaluated together with the measurement of testicular androgens. Therefore, one may have expected a similar response in the subjects in this study post-injury, however testicular androgens were not measured in this study.

Another important finding in this study is the confirmation of the endogenous production of small amounts of nandrolone metabolites in the urine post-injury and at baseline(Table 3.6). This is in agreement with the findings of various other studies in humans. $10 ; 20 ; 28 ; 28 ; 43 ; 48 ; 51 ; 72 ; 75 ; 79 ; 93$ The above findings are also consistent with other studies which have found that 19-NA is the most abundant metabolite of nandrolone 
and is excreted in the urine in higher concentrations compared to $19-N E$. $5 ; 17: 59 ; 67 ; 78$ (Table 3.6) 19 NE concentrations were undetectable in the urine of some subjects, which is also consistent with other study findings. ${ }^{20 ; 28}$ The results from this study also show that there was a wide inter-individual variation in the excretion of both 19-NA and 19-NE in the urine. ${ }^{20 ; 51 ; 79}$

In conclusion, this study has confirmed that individuals free of nandrolone can produce small amounts of 19-NA and 19-NE in the urine. Furthermore, when all the data are combined and analyzed, musculoskeletal injury does not significantly affect the concentration of 19-NA and 19-NE in the urine of male subjects. However, when data are analysed individually, there may be a small chance that an athlete may exceed the IOC cut-off concentration for 19-NA in the urine after sustaining a musculoskeletal injury. The mechanism explaining this needs further investigation so that the $10 \mathrm{C}$ guidelines for a positive nandrolone test can be adjusted to reduce the risk of an athlete having a false positive test for nandrolone. 


\section{CHAPTER 4}

\section{SUMMARY AND CONCLUSION}

In summary, in accordance with the aims of the thesis, the following can be concluded:

- To validate the International Olympic Committee's cut-off concentration for urine 19-NA of $2 \mathrm{ng} \cdot \mathrm{ml}^{-1}$ in male subjects immediately after sustaining musculoskeletal injury.

It was further demonstrated that one of the male subjects, who was free of synthetic nandrolone, produced a 19-NA urine concentration of $2800 \mathrm{pg} \cdot \mathrm{ml}^{-1}$ immediately after musculoskeletal injury. This 19-NA concentration exceeded the cut-off concentration of $2000 \mathrm{pg} \cdot \mathrm{ml}^{-1}$ set by the $10 \mathrm{C}$. This may represent a 1 in 32 chance that an athlete who has sustained musculoskeletal injury after competition may produce a false positive nandrolone drug test result.

Based on the results from this study it is recommended that further similar studies be conducted to investigate the possible relationship between severe physiological stress and the excretion of nandrolone metabolites in the urine. It is also recornmended that consideration be given by the $10 \mathrm{C}$ to use more sophisticated analytical techniques to distinguish endogenous from synthetic nandrolone in drug testing laboratories. This study highlights that it may be unethical to drug test competitive athletes after sustaining severe musculoskeletal injury and that other testing methods could be used as adjuncts to confirm nandrolone administration, namely isotope ratio mass 
spectrometry, hair analysis ${ }^{23}$ or analysis for the particular type of the steroid conjugate. $^{49}$

To determine whether moderately active male subjects who sustain severe physiological stress (musculoskeletal injury) can excrete nandrolone metabolites (19-NA and 19-NE) in the urine in higher concentrations compared to baseline.

The concentration of 19-NA and 19-NE in the urine of moderately active male subjects did not change significantly in all subjects after musculoskeletal injury when compared to baseline.

To confirm the endogenous production of 19-NA and 19-NE in the urine of moderately active male subjects.

This study confirmed the endogenous production of small amounts of 19-NA and 19NE in the urine of male populations who have not administered nandrolone. 


\section{REFERENCES}

1. Ayotte C. Nutritional supplements and doping controls. IAAF New Studies in Athletics $1999 ; 14: 37-42$.

2. Baker SP, O'Neill B, Haddon $\mathrm{W}$, Jr, et al. The injury severity score: a method for describing patients with multiple injuries and evaluating emergency care. $J$ Trauma $1974 ; 14: 187-196$

3. Bambino $\mathrm{T}$ and Hsueh A. Direct inhibitory effect of glucocorticoid upon testicular luteinizing hormone receptor and steroidogenesis in vivo and in vitro. Endocrinology 1981; 108:2142-2148.

4. Barton RN, Stoner HB, Watson SM. Relationships among plasma cortisol, adrenocorticotrophin, and severity of injury in recently injured patients. $J$ Trauma 1987; 27:384-392.

5. Belkein L, Schurmeyer T, Hano R, et al. Pharmacokinetics of 19nortestosterone esters in normal men. J Steroid Biochem 1985; 22:623-629.

6. Berkovitz GD, Guerami A, Brown TR, et al. Familial gynecomastia with increased extraglandular aromatization of plasma carbon 19-steroids. J Clin Invest 1985; 75:1763-1769.

7. Bjorkhem $\mathrm{E}$ and $\mathrm{EkH}$. Detection and quantitation of 19-norandrosterone in the urine by isotope dilution-mass spectrometry. J Steroid Biochem 2002; 17:447451. 
8. Brilla L.R. and Conte V. Effect of a novel zinc-magnesium formulation on hormones and strength. J Exerc Physiol 2002; 3:26-36.

9. Castro-Magana M, Collipp PJ, Chen SY, et al. Zinc nutritional status, androgens, and growth retardation. Am J Dis Child 1981; 135:322-325.

10. Catlin DH, Leder BZ, Ahrens B, et al. Trace contamination of over-the-counter androstenedione and positive urine test results for a nandrolone metabolite. JAMA 2000; 284:2618-2621.

11. Clarkson PM. Minerals: exercise performance and supplementation in athletes. $J$ Sports Sci 1991; $9: 91-116$.

12. Conley A, Corbin C, Hinshelwood M. Functional aromatase expression in porcine adrenal gland and testis. Biol Reprod 1996; 54:497-505.

13. Cordova $A$ and Navas FJ. Effect of training on zinc metabolism: changes in serum and sweat zinc concentrations in sportsmen. Ann Nutr Metab 1998; 42:274-282.

14. Cowan DA, Kicman AT, Walker CJ, et al. Effect of administration of human chorionic gonadotrophin on criteria used to assess testosterone administration in athletes. J Endocrinol 1991; 131:147-154.

15. Cumming DC, Brunsting $L A$, Strich $G$, et al. Reproductive hormone increases in response to acute exercise in men. Med Sci Sports Exerc 1986; 18:369-373.

16. De Cock KJ, Delbeke FT, Van Eenoo P, et al. Detection and determination of anabolic steroids in nutritional supplements. JPharm Biomed Anal 2001; 25:843-852 
17. Debruyckere $G$, de Sagher $R$, De Leenheer A, et al. The impact of nandrolone metabolites occurring in normal male urines, effect of the cut-off level stipulated for nandrolone doping. In: Gorog S, ed. Proceedings of the fourth symposium on the analysis of steroids, August 1990, Budapest. Budapest: Pecs, Akademie Kiado, 1990:363.

18. Debruyckere $G$ and Van Peteghem $C$. Influence of the consumption of meat contaminated with anabolic steroids on doping tests. Analytica Chimica Acta $1993 ; 275: 49-56$.

19. Debruyckere $G$, de Sagher R, Van Peteghem C. Clostebol-positive urine after consumption of contaminated meat. Clin Chem 1992; 38:1869-1873.

20. Dehennin L, Bonnaire $Y$, Plou P. Urinary excretion of 19 -norandrosterone of endogenous origin in man: quantitative analysis by gas chromatography-mass spectrometry. J Chromatogr B Biomed Sci Appl 1999; 721:301-307.

21. Dehennin L, Jondet M, Scholler R. Androgen and 19-norsteroid profiles in human preovulatory follicles from stimulated cycles: an isotope dilution-mass spectrometric study. J Steroid Biochem Mol Biol 1987; 26:399-405.

22. Dollers $C$. Therapeutic drugs. Edinburgh: Churchill Livingstone, 1991; 2: N25N29.

23. Dumestre-Toulet $V$, Cirimele $V$, Ludes $B$, et al. Hair analysis of seven bodybuilders for anabolic steroids, ephedrine and clenbuterol. J Forensic Sci $2002 ; 47: 211-214$ 
24. Elman I and Breier A. Effects of acute metabolic stress on the plasma progesterone and testosterone in male subjects: relationship to pituitaryadrenocortical axis activation. Life Sci 1997; 61:1705-1712.

25. Evain D, Morera A, Saez J. Glucocorticoid receptors in interstitial cells of rat testis. J Steroid Biochem 1976; 7:1135-1139.

26. Fishman J. Biochemical mechanism of aromatisation. Cancer Res 1982; 42:3277-3280.

27. Galan Martin AM, Maynar Marino JI, Garcia de Tiedra MP, et al. Determination of nandrolone and metabolites in urine samples from sedentary persons and sportsmen. J Chromatogr B Biomed Sci Appl 2001; 761:229-236.

28. Gambelunghe C, Sommavilla.M, Rossi R. Testing for nandrolone metabolites in urine samples of professional athletes and sedentary subjects by GC/MSMS analysis. Biomed Chromatogr 2002; 16:508-512.

29. Ganong WF. Review of Medical Physiology. Connecticut, USA: Lange Medical Book, 1999; 17:283; 19: 345-360.

30. Gillies H, Derman WE, Noakes TD, et al. Pseudoephedrine is without ergogenic effects during prolonged exercise. J App/ Physio/ 1996; 81:2611-2617.

31. Hagensen-Jetne, Misund $J$, Hemmersbach P. Determination of urinary norandrosterone excretion in females during one menstrual cycle by GC/MS. Pittcon Conf. 2000: abstract 585.

32. Haupt HA and Rovere GD. Anabolic steroids: a review of the literature. Am J Sports Med 1984; 12:469-484. 
33. Hawley JA, Dennis SC, Lindsay FH, et al. Nutritional practices of athletes: are they sub-optimal? J Sports Sci 1995; 13:S75-S81.

34. Hickson RC, Ball KL, Falduto MT. Adverse effects of anabolic steroids. Med Toxicol Adverse Drug Exp 1989; 4:254-271.

35. Horton $R$ and Tate J. Androstenedione production and the interconversion rates measured in the peripheral blood and studies on the possible site of conversion to testosterone. J Clin Invest 1996; 45:301-313.

36. International Olympic Committee. Criteria for reporting low concentrations of anabolic steroids. Intemational Olympic Committee document. 1998:Aug 1:appendix 4.

37. James, VHT. UK Sports Nandrolone Review. London: UK Sports Council, January 2000.

38. Kamber M, Baume N, Rivier L. Nutritional supplements as a source for positive doping cases. Int J Sport, Nutrition and Exerc Metab 2001; 11:258.

39. Khaled S, Brun JF, Micallel JP, et al. Serum zinc and blood theology in sportsmen (football players). Clin Hemorheol Microcirc 1997; 17:47-58.

40. Kicman AT and Brooks RV. A radioimmunoassay for the metabolites of the anabolic steroid nandrolone. J Pharm Biomed Anal 2002; 6:473-483.

41. Kicman AT, Brooks RV, Collyer SC, et al. Criteria to indicate testosterone administration. Br J Sports Med 1990; 24:253-264. 
42. Kintz P. Hair testing and doping control in sport. Toxicology Lett 1998; 102:109113.

43. Kintz P, Cirimele V, Ludes B. Norandrosterone and noretiocholoanolone is this doping? Acta Clinica Belg Supplements 1999; 1:68-73.

44. Kintz P, Cirimele V, Dumestre-Toulet V, et al. Doping control for nand rolone using hair analysis. J Pharm Biomed Anal 2001; 24:1125-1130.

45. Kraemer RR, Kilgore JL, Kraemer GR, et al. Growth hormone, IGF-I, and testosterone responses to resistive exercise. Med Sci Sports Exerc 1992; 24:1346-1352.

46. Lamb DR. Androgens and exercise. Med Sci Sports Exerc 1975; 7:1-5.

47. Lambert M and St Clair Gibson A. Androgenic-anabolic steroids: effects on muscle size and strength. S A J of Sports Med 1995; 2:6-8.

48. Le Bizec, B., Bryand, F., Gaudin, I, et al. Endogenous nandrolone metabolites in human urine. Two year monitoring of professional soccer male players. $J$ Anal Toxicol (in press).

49. Le Bizec B, Bryand F, Gaudin I, et al. Endogenous nandrolone metabolites in human urine: preliminary results to discriminate between endogenous and exogenous origin. Steroids 2002; 67:105-110.

50. Le Bizec B, Gaudin I, Monteau F, et al. Consequence of boar edible tissue consumption on urinary profiles of nandrolone metabolites. I. Mass spectrometric detection and quantification of 19-norandrosterone and 19- 
noretiocholanolone in human urine. Rapid Commun Mass Spectrom 2000; 14:1058-1065.

51. Le Bizec B, Monteau F, Gaudin I, et al. Evidence for the presence of endogenous 19-norandrosterone in human urine. J Chromatogr B 1999; $723: 157-172$.

52. Leder $\mathrm{BZ}$, Longcope $\mathrm{C}$, Catlin $\mathrm{DH}$, et al. Oral androstenedione administration and serum testosterone concentrations in young men. JAMA 2000; 283:779782.

53. Lewis JG, Ghanadian R, Chisholm GD. Serum dihydrotestosterone and testosterone changes with age in man. Acta Endocrinol. 1976; 82:444-448.

54. Longcope C, Kato T, Horton R. Conversion of blood androgens to estrogens in normal adult men and woman. J Clin Invest 1969; 48:2191-2201.

55. MacConnie SE, Barkan A, Lampman RM, et al. Decreased hypothalamic gonadotropin-releasing hormone secretion in male marathon runners. $N$ Engl J Med 1986; $315: 411-417$.

56. Maclndoe $\mathrm{JH}$, Perry PJ, Yates WR, et al. Testosterone suppression of the HPT axis. J Investig Med 1997; 45:441-447.

57. Makin H. Biochemistry of Steroid Hormones. Blackwell Scientific publications, $1975 ; 11: 250-271$

58. Mareck-Engelke U, Geyer H, Schanzer W. Recent Advances in Doping Analysis. Cologne: Sport und Buch Strauss, 1998:119. 
59. Masse $\mathrm{R}$, Laliberte $\mathrm{C}$, Tremblay L, et al. Gas chromatographic/mass spectrometric analysis of 19-nortestosterone urinary metabolites in man. Biomed Mass Spectrom 1985; 12:115-121.

60. Mathurin JC, Herrou V, Bourgogne E, et al. Gas chromatography-combustionisotope ratio mass spectrometry analysis of 19-norsteroids: application to the detection of a nandrolone metabolite in urine. $J$ Chromatogr B Biomed Sci Appl $2001 ; 759: 267-275$.

61. Milanov, S. Tribestan effect on the concentration of some hormones in serum of heatthy subjects.(Unpublished data)

62. Milewich $\mathrm{J}$ and Axelrod A. Testosterone metabolism by placental microsomes from baboons: identification of 19-nortestosterone and 19-nor-4androstenedione. J Steroid Biochem Mol Biol 1979; 10:241-243.

63. Morgan W. On evidence, embellishment and efficacy. J Eval Clin Pract 1997; $3: 117-122$.

64. Nel, S. Springbok rugby player tests positive for steroids. Cape Times, 2000 Nov 26.

65. Olympic Movement. Olympic Movement Anti-Doping Code 1999: Appendix A prohibited classes of substances and prohibited methods. Switzerland: IOC Lausanne, 2001.

66. Osawa, $\mathrm{Y}$ and Yarborough, C. Non-aromatizing androgen C10-19 lyase: biosynthesis of 19-norandrostenedione by the dog adrenal. 65th Annual Meet of the Endocrin Soc. 1983664. 
67. Ozer D and Temizer A. The determination of nandrolone and its metabolites in urine by gas chromatography-mass spectrometry. Eur J Drug Metab Pharmacokinet 1997; 22:421-425.

68. Padron RS, Wischusen J, Hudson B, et al. Prolonged biphasic response of plasma testosterone to single intramuscular injections of human chorionic gonadotropin. J Clin Endocrinol Metab 1980; 50:1100-1104.

69. Petraglia F, Vale W, Rivier C. Opiods act centrally to modulate stress-induced decrease in luteinizing hormone in the rat. Endocrinology 1986; 119:2445-2450.

70. Pomerantz DK. Human chorionic gonadotropin enhances the ability of gonadotropic hormones to stimulate aromatization in the testis of the rat. Endocrinology 1981; 109:2004-2008.

71. Prasad AS, Mantzoros CS, Beck FW, et al. Zinc status and serum testosterone levels of healthy adults. Nutrition 1996; 12:344-348.

72. Reznik $Y$, Dehennin L, Coffin $C$, et al. Urinary nandrolone metabolites of endogenous origin in man: a confirmation by output regulation under human chorionic gonadotropin stimulation. J Clin Endocrinol Metab 2001; 86:146-150.

73. Reznik $Y$, Herrou M, Dehennin L, et al. Rising plasma levels of 19nortestosterone throughout pregnancy: determination by radioimmunoassay and validation by gas chromatography- mass spectrometry. J Clin Endocrinol Metab 1987; 64:1086-1088. 
74. Ringstrom S and Schwartz N. Cortisol suppresses the LH, but not the FSH response to gonadotropin-releasing hormone after orchidectomy. Endocrinology 1985; 116:472-474.

75. Robinson N, Taroni F, Saugy M, et al. Detection of nandrolone metabolites in urine after a football game in professional and amateur players: a Bayesian comparison. Forensic Sci In. 2001; 122:130-135.

76. Ryan A. Anabolic-androgenic steroids. Berlin, Heidelberg: Springer-Verlag $1976,515-533$.

77. Saugy, $M$, Robinson, $N$, and Cardis, $C$, et al. Nandrolone metabolites in formal competition tests. FIFA Sports Medical Committee.

78. Schanzer W and Donike M. Metabolism of anabolic steroids in man: synthesis and use of reference substances for identification of anabolic steroid metabolites. Analytica Chimica Acta 1993; 275:23-48.

79. Schmitt N, Flament M, Goubault C, et al. Nandrolone excretion is not increased by exhaustive exercise in trained athletes. Med Sci Sports Exerc 2002;

$34: 1436-1439$

80. Schmitt W, Kindermann W, Schnabel A. Testosterone blood level and physical exercise. Int J Sports Med 1982; 22:84.

81. Woolf, P. Hormonal responses to trauma. Criti Care Med 1992; 20(2):216-226.

82. Segura, J. Letter of Information to the Heads of $10 \mathrm{C}$ Accredited Laboratories. Barcelona, August 221996. 
83. Shackleton $\mathrm{CH}$, Phillips $\mathrm{A}$, Chang $\mathrm{T}$, et al. Confirming testosterone administration by isotope ratio mass spectrometric analysis of urinary androstanediols. Steroids 1997; 62:379-387.

84. Smals AG, Pieters GF, Lozekoot DC, et al. Dissociated responses of plasma testosterone and 17-hydroxyprogesterone to single or repeated human chorionic gonadotropin administration in normal men. J Clin Endocrinol Metab $1980 ; 50: 190-193$.

85. Stoner HB, Frayn KN, Barton RN, et al. The relationships between plasma substrates and hormones and the severity of injury in 277 recently injured patients. Clin Sci 1979; 56:563-573.

86. Sulcova J, Rafter J, Stuka L. 19-nortestosterone in mouse kidney. Endocrinol Experim 1979; 13:225-235.

87. Sutton JR, Coleman MJ, Casey J et al: Androgen responses during physical exercise. BMJ 1973; 1:520 522.

88. Suvisaari J, Sundaram $\mathrm{K}$, Noe $\mathrm{G}$, et al. Pharmacokinetics and pharmacodynamics of 7 alpha-methyl-19-nortestosterone after intramuscular administration in healthy men. Hum Reprod 1997; 12:967-973.

89. Titlestad S, Lambert M, Schwellnus M. A survey to determine types and dosages of anabolic-androgenic steroids used by competitive bodybuilders in South Africa. SA J of Sports Med 1994; 2:6-9. 
90. Uralets VP and Gillette PA. Over-the-counter anabolic steroids 4-androsten-

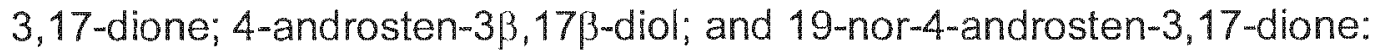
excretion studies in men. J Anal Toxicol 1999; 23:357-366.

91. Uralets VP and Gillette PA. Over-the-counter $\Delta^{5}$ anabolic steroids 5-androsen3,17-dione; 5-androsten-3 $\beta, 17 \beta$-diol; dehydroepiandrosterone; and 19 nor-5androsten-3,17-dione: excretion studies in men. J Anal Toxicol 2000; 24:188193.

92. van der Merwe P and Grobbelaar E. Stability of 19-norandrosterone and 19noretiocholanolone glucuronide in urine under various storage conditions. SA J of Sports Med 2003; 15:14-17.

93. Van Eenoo P, Delbeke FT, de Jong FH, et al. Endogenous origin of norandrosterone in female urine: indirect evidence for the production of 19 norsteroids as by-products in the conversion from androgen to estrogen. $J$ Steroid Biochem Mol Biol 2001; 78:351-357.

94. Viro A. Hormones in Muscular Activity. Florida, USA, CRC Press, 1985; 4: 8589.

95. Vogel RB. Increase of free and total testosterone during submaximal exercise in normal males. Med Sci Sports Exerc 1985; 17:119-123.

96. Wilkerson JE, Horvath SM, Gutin B. Plasma lestosterone during treadmill exercise. J App/ Physiol 1980; 49:249-253.

97. Young J, Bulun S, Agarwal V. Aromatase expression in a feminizing adrenocortical tumour. J Clin Endrocrinol Metab 1996; 41:13-20. 


\section{APPENDICES}

Appendix A: Informed consent - English.

Appendix B: Informed consent - Xhosa.

Appendix C: $\quad$ Informed consent - Afrikaans.

Appendix D: $\quad$ Exclusion Criteria.

Appendix E: $\quad$ Demographic information and health assessment.

Appendix F: $\quad$ Training history and training diary.

Appendix G: Urine nandrolone metabolites: false positive doping test? $\mathrm{Br}$ J Sports Med 2002; 36:325-329.

Appendix H: Ethics approvalletter from the University of Cape Town. 


\section{Appendix A}

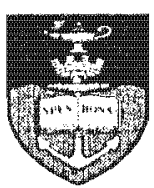

\section{Informed consent form}

MRC/UCT Research Unit for Exercise Science and Sports Medicine, Department of Human Biology, University of Cape Town, Sports Science Institute of South Africa

1 am fully aware that my injury will be diagnosed and treated according to standard medical practice at Milnerton Medi-Clinic. I am also aware that I will need to:

- Submit a urine sample for hormone testing (nandrolone metabolites).

- Submit a blood sample for hormone testing (cortisol, luteinizing hormone).

The possible risks and complications of a blood test have been explained to me. I am aware that I may withdraw my consent and stop taking part in the research study at any time.

I understand that the information collected may be used for scientific purposes and publication but that my confidentiality will be respected at all times during the study and when the report is published.

I understand the implications of my informed consent and any questions I may have had have been answered to my satisfaction.

Name:

Signed:

Date:

Researcher: Signed: Date:

Witness: Signed: Date: 


\section{Appendix B:}

\section{Ifomu yesivumelwano esazisayo}

MRC/UCT lyuniti Yezophando Kwinzuluwaziyothambo Nobugqirha bezemidlalo Isebe le Nzululwazi ya Buntu

IYunivesithi yaseKapa

Iziko le Nzululwazi laseMzantsi Afrika

Mna ndaziswe ngokupheleleyo ngohlobo lolu phando kwaye ndinika imvume yokuba ndisetyenzsiswe kolu phando.

Ndiqonda ngokupheleleyo iinkqubo ezisetyenziswayo:

- Ukunikezela ngomchamo ukuvavanya incindiyedlala (nandrolone metabolites).

- Ukunikezela ngegazi ukuvavanya yedlala (cortisol, luteinizing hormone).

Ndicaciselwe ngobungozi nobumzima bokuthatha uvavanyo Iwegazi.

Ndiyaqonda ukuba ndingarhoxa kwisivumelwano kwaye ndiyeke ukuthatha inxaxheba kolu phando naninina.

Ndiyaqonda ukuba ulwazi oluqokelelweyo lungasetyenziswa kwinjongo zenzuluwazi nokushicilelwa ngendlela eyimfihlo.

Ndiqonda nesibophelelo sesi sivumelelwano esazisayo kwaye imibuzo ebendinayo iphendulwe ngendlela endonelisayo.

Igama Sayina Umhla

Umphandi Sayina Umhla

Ingqina Sayina Umhla

"This document has been translated by Mrs Rose Smouse, Lecturer, Department of African Languages, University of Cape Town. 


\section{Appendix C:}

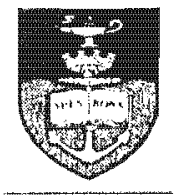

\section{Toestemmingsform}

Ek is ten volle ingelig oor die beginsels van hierdie studie en gee hiermee my vrywillige toestemming om as proefpersoon aan die studie deel te neem.

Ek is ten volle bewus van die betrokke prosedures wat van my verwag word naamlik:

- Verskaffing van 'n urienmonster vir hormoontoetsing( nandrolone metabolites).

- Verskaffing van 'n bloedmonster vir hormoontoetsing (cortisol, luteinizing hormone).

Die potensiële risiko's en komplikasies van die bloedtrekprosedure is aan my verduidelik. Ek is bewus daarvan dat ek ten enige van hierdie studie kan onttrek.

Ek verstaan dat die ingesamelde informasie vir wetenskaplike doeleindes gebruik sal word en in 'n konfidensiële manier hanteer en gepubliseer sal word.

Ek verstaan die implikasies van my ondertekende toestemming en voel tevrede dat al my vrae ten volle beantwoord is.

Naam:

Geteken:

Datum:

Navorsers:

Geteken:

Datum:

Getuie:

Geteken:

Datum:

"This document was kindly translated by Miss Amanda Claassen. 


\section{Appendix D:}

\section{Exclusion criteria}

- Age younger than 18 years and older than 50 years.

- Female.

- Sedentary lifestyle.

- Injury severity score (ISS) $>13$.

- Participation in competitive bodybuilding or power lifting.

- Previous use of prohormone supplements.

- Previous use of androgenic anabolic steroids.

- Previous positive drug test in sport and suspension from sports competition.

- Abnormal blood screening parameters (luteinizing hormone).

- Medical illness (asthma, cardiovascular disease, renal disease, prostate disease, breast cancer, liver disease).

- Medications known to affect steroid hormone concentrations e.g. all forms of hormone replacement therapy. 


\section{Appendix E:}

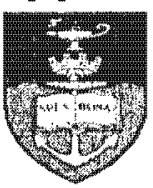

Demographic information and health assessment

Subject number:

Name:

Address:

code

Phone:

(w)

(h) (cell)

Email:

Age (years):

Height $(\mathrm{cm})$ :

Body mass $(\mathrm{kg})$ :

Anthropometric data:

- Thigh girth $(\mathrm{cm})$

- Thigh skinfold (mm)

- Calf girth $(\mathrm{cm})$

- Calf skinfold (mm)

- Forearm girth $(\mathrm{cm})$

- Forearm skinfold (mm)

Medical history

How did the injury occur (mechanism)? 
Where is the injury (body part)?

Describe the symptoms in full:

What time did the injury occur?

What time were the blood and urine samples taken?

Were you exercising at the time? Yes No

If Yes, please give details (type of activity, duration, intensity):

Do you have any allergies? yes no

If yes, please explain:

Are you using any medications? yes

no

If yes, please explain:

Do you smoke? yes

no

If yes, state the number/day:

Describe any previous surgical procedures:

Do you have any medical illnesses? 
Medical examination:

(a) general examination

b) systems examination 


\section{Appendix F:}

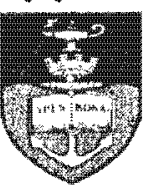

\section{Training history and training diary}

Training history: (last 3 months)

Endurance training:

Average duration per day ( $\mathrm{min}$ ) in the last 3 months:

Average number of times per week in the last 3 months:

Resistance training:

Average duration per day (min) in the last 3 months:

Average number of times per week in the last 3 months:

Training diary:

\begin{tabular}{|l|l|l|l|l|}
\hline Day & Date & Duration & Intensity & Type \\
\hline Monday & & & & \\
\hline Tuesday & & & & \\
\hline Wednesday & & & & \\
\hline Thursday & & & & \\
\hline Friday & & & & \\
\hline Saturday & & & & \\
\hline Sunday & & & & \\
\hline
\end{tabular}




\title{
REVIEW
}

\section{Urine nandrolone metabolites: false positive doping test?}

\author{
R M N Kohler, MI Lambert
}

BrJ Sports Med 2002;36:325-329

The aim of this review is to analyse the studies on nandrolone metabolism to determine if it is possible for an athlete to test positive for nandrolone without having ingested or injected nandrolone.

\begin{abstract}
T anabols ardrogertc sterod 19 nortesfosterone, also onled mandrolone, was furst synthesised by Bud in 1950. Nan drolone has an anabolc efect, and is used in the treatmen of cerain chonte diseases. the he of natholone by athetes became popular in the hate

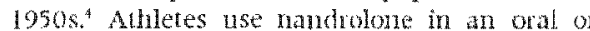
injectable form to increase unscle strengeh and inturove performance. As a result of the potertial portomance enthancing betefits and potential healur risk assomated with anablic steroid nse, the International olympic Conmitte $(10 \mathrm{C})$ po Whited the use of nandrolone in sport in 1976.
\end{abstract}

"A doping offence for nandrolone was delined as a concentration of NA in human urine axcoeding $2 \mathrm{ng} / \mathrm{m}$ in men and 5 $\mathrm{ng} / \mathrm{ml}$ in women

When nandrolone is ingested or injected by humans suljects, three netabolites of than drolone can be isolated and neasured in the wine by gas chmotography-nass spectromeny these matabolites have been identilied as 19 worandrosteront $1 \mathrm{NA}$; $3 \alpha$-hyloxy-5a-bestru

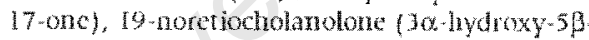
oxstan-17-one), and 19-10reviandosterone (3)-bydroxy-5a-oestran-17-one). These me tabolites are isoneric compoums, having the same chemical compostion and molecuar mass

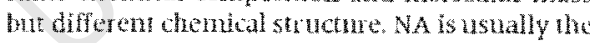
most abundant inthe metabulte of

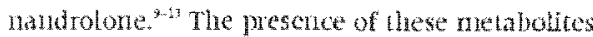
in une unine forms the basis of doung analysts for the lllegal nste of nandrotone by athetes. This was based on the premise llat thess mine netabolites colld only have ben derived from agonous nandrolone. A study in 1982 appeared to have found $N A$ or a similar commound, in the wine of athletes who had nor used nandrolone: In 1996, 1he 106 stated that a oitical concentu

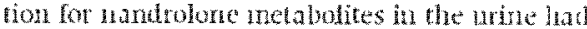
been establshed. A doping offence for nay drolone was defined as a concentration of $\mathrm{NA}$ in luman urine erceding, $2 \mathrm{mghn}$ th men and 5 ngtwin in women."

\footnotetext{
"Recenly, the possibility of folse positive
} tests lor nondrolone has been rolsed.
Recenty, the possibility of lalse positive tests for nandrolone has been raised. Fxplanations for labe positive tests have induded supplement cmamination ${ }^{\text {*a }}$ and endogenous production of randrolone and regulation of netabulc pathways of randrolone netabolsm by whons physiologi cal factors and supplement interventous. The aim of this revicw is to analys the sudies on nandrolme metabolism win the wenll gon of determining whether in is indeed lussthe for an allete to test posilive lor mandrolone whlout having elthe ingested or injected haturolone. The question of a posily to tresulting hom mitritional suplements is and foot contamination ${ }^{10}$ is bevont the scope of this review.

\section{EVIDENCE FOR ENDOGENOUS NA}

"The origir of endogenous NA in lle whine of athletes who have not knowingly ingested or injected nandrolone is central to resolving the question of whether it is possible to have a false mositive last. The first sudy to suggest that $\mathrm{NA}$ conll be foum in the wine of people free of wogenous naxdrolone was a study on laboratory staff $/ \mathrm{H}=$ 14). "Then unime was analysed using tsotope dinton mass spentometry, and $\mathrm{NA}$ or a simlar com. pount was suspected. This snspicion was based on the detection of anal peak for the ion at whit $256{ }^{*}$ In retrospect, this signal may have ben caused by interference of other endogenous conpounds (noise) and perhaps represtuts a false positive finding. The anthors achowwedged the limitations of the study, the andytical technique lacking specilicty and sensivity.

Studies in 1088 and 1990 again raised the possibility of entogenous NA in th: urite of

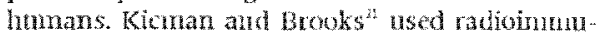
moassay and measured $\mathrm{NA}$ in the lrine of nen and women, who were snpposenly free of exogenous nandrolone, ranying from 3.8 to 45.4 ngm. However, these data shoull be merpreted will caution as if cond be argued that the analytical techntu agan lacks both specificy and sensinvily Defroycker at measured NA in the urine of thee subjects at concentrations of 9, 14 , and $37 \mathrm{ng} / \mathrm{ml}{ }^{21}$ These results were late arributed to nandrolone contaminated neal Which the subjects may have saten.

In 1996, the roc declared that he presence of a suall amount of $\mathrm{A}$ in the wrine by not const ered to constime a doning offence." This suggests that they ackrowitedged the possibily

Abbraviatons: $10 \mathrm{C}$, Internationd Oymoic Committer

NA, 19 morendrosterona; GCLAMS, gas

drondograohycombution-isotope rato mess spectromety 


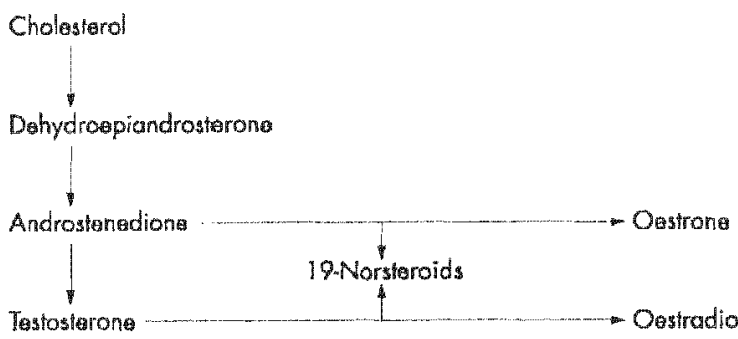

Figure 1 the androgen biosynhelic poltwey and the proposed aromatisation of androgen to oestrogen with the formation of 19-rorileroid inlemediates.

of endogenous $N A$ production. It can only be assumed that this dicision was reached on the basis of data collected by $\mathrm{rOC}$ laboratories during routine drug lesting, as the scientific evidence at the tine was equivocal. Th the late 1990s, andytical procedures for the detection and quantification of steroid metalohtes in urine tad bicome increasingly seusitive. ${ }^{27}$ lins may tave accomnted for an appreciabie number of positive urine samples for $\mathrm{N} A$ being analysed in certain anti-doping laboratories. Many of the positive samples were from partici pants of sports that had previonsly not been associated with anabolic steroid use.' Further resendr with more sensitive equipment was underaken to determine if NA conk be produced naturally by the hmman body. This reseach showed convincing evidence that $\mathrm{NA}$ was found in the urine of subjects free of exogenous nandrolone. ${ }^{15}$ to the-2A The urine NA concentrations in these studies ranged from 0.01 to 1.79 $\mathrm{ng} / \mathrm{mnl}$. In a study by Galan Martin $t$ al $l_{2}{ }^{27}$ high $N \mathrm{~A}$ concentrations in tive sportspeople $(4,5,6,8$, and $14 \mathrm{ng} / \mathrm{ml})$ were measured. One woman in the study, who was posmenopausal, had a NA concentraton of $22 \mathrm{ng} / \mathrm{ml}$. It could be argued that these athetes had administered nandrolone. ${ }^{24}$ These results are diffoult to explain and perlaps further investigation of these subjects is necessary before a definite opinion can be formed.

\section{METABOLISM OF NA}

\section{Aromatisction}

Metalyolic pathways for the endogenons production of NA in the human body need to $k^{\circ}$ conshilered. Under normal circmustances, testosterone is aromatised to vestrogen by the aromatase enzyme complex.". Androstenedione, the direct precursor of listosterone, is also aromatised to oestrogen by the aromalase enzyme. ${ }^{31}$. The important step in this netaklic process is the removal of the nethyl group from the 19til carbon of teither testosterone or androstenedione. Nandrolone differs struciurally from testosterone and andros. tenedione in lacking the methyl group at the 19 he carbon, and it is wditionally dilferent from androstenedione in substitntion of a ketone gromp for an hydroxy group at the $17 \mathrm{~h}$ carbon. Is it fensible that 19-11orsteroids (nandrolone and metabolites) are intermediates in the aromatisation process? (fig 1$)$.

Animal sudies, in vitro experinnents, and observations in Immars, particularly pregnant wornen, add support to the moposa] that 19-norsteroids ane internediates in the aromatisation of androgens to oestrogen. ${ }^{\circ}$ is is 21 as 26 31-57 Oestrogen concentrations in women increase significanty both at the time of onnlation and during pregrancy, ${ }^{263}$ Raised urine $N A$ concentrations liave recently been identified in women at the time of ovelation ${ }^{26}{ }^{19}$ and during pregnancy ${ }^{\text {in }}$ Mareck-lingelke et at $t^{n}$ teponted that during pegnancy the concentration of $\mathrm{NA}$ in human urine rray reach $20 \mathrm{ng} / \mathrm{rl}$. In these cases, pregnancy is confmued with a blool test for hman chorionic gonalotroplun.
A recent sindy by Reanik of a $t^{25}$ cxamined the sequelae of giving human chorionic gonadotrophin to $30 \mathrm{men}$. Imom chorionic gonadotrophin increases strmo testosterone in healthy mentis and stimulates the aromatase enzyme, causing a gradual increase in senm bestrogen ${ }^{40+45}$ The serum testosterone and oestrogen increased in the 10 subjects after human chorionic gondotrophin adnuistration, and NA excretion in the urine increased by $250 \%$. It thay be conduded from this stuly that the increase in nandrolonc bosynthesis was possibly associated will the increased aromatisation of testosterone to oestrogen.

"Factors that could increase the flux of androgen precursors through the lestosterone biosynthetic pathway could theoretically increase the amount of nandrolone produced."

Although the pathways proposed are theoretical, the avail able evidence suggests that it is possible for the flux of androgen precursors throngh the testosterone biosynthetic parlway to result in the production of endogenous nandrolone. Therefore it can beassumed that facors that could increase the lux of androgen precursors through the testosterone biosynthetic wathway could theoretically increase the amount of nandrolone produced.

\section{FACTORS WITH THE POTENTIAL TO AFFECT NA METABOLISM}

Genetics

There is a wide range of scrurn testosterone concentrations in man, ${ }^{33}$ suggesting large genetic interindivhal and intraindividual variability in sex steroid production and excretion over a 2 hour period." The possibility therefore exists that there is a variable rate of $\mathrm{NA}$ excrelion, mated, chdogenoms NAmine excretion in a male atluete varied by $680 \%$ over a three mum period and in another subject by $72 \%$ over a 24 hour period. The enyme complex 17/-hydroxysteroid dehylogenase, which is responsible for conver tirg androsternedione into tes costerone, and the aromatase enzyme complex, which converts testosteronc into oestrogen, occur in muscle and fat." Therefore, it is concelvable that people with higher unscle and fat content may be more proficient in the produc hon of 19-norsteroid intermediates. The aromatase tnzyme complex per se can also show considerable genetic variability in expression and activity in certain people, wilh increased activity of the aromatase enzyme producing larger anumus of oestrogen. This prompts the question of whether genetic upregulation of the aromatisation process in these people increasts the production of 19 -norsteroids.

\section{Exercise}

Intense exerise has been associated with raised levels of $\mathrm{NA}$

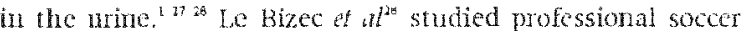
players over 19 months and collected 385 mine samples. Urine NA concentrations alter soccer ganes were signilicantly higher than before games. For NA concentrations after ganes, $70 \%$ of the urine samples were below $0.1 \mathrm{ng} / \mathrm{ml}$, and $20 \%$ wer between 0.1 and $0.2 \mathrm{lg} / \mathrm{ml}$. NA in fou nine samples wet alwove $1.0 \mathrm{rg} / \mathrm{ml}$, the nuximm vahe heing $1.79 \mathrm{ng} / \mathrm{ml}$. When unine is tested for banled substances and the specific gravity of the unine sample is neasured above 1.020 , minc metabolite concentrations are adjusted by a correction factor." This andysis is based on the premise that mint llow rate and unine netabolite excretion remain constant during and arectly after exercise. However, this is an erroneous assunpulon as it has been shown that corction of pseudoephedrine after exer cise was increased in subjects in twom unine volume remained constant." Thus urine metabolite exctetion may not remain constant during and arectly after exucise and 
ranton urinc sample collection after exercise may be unreliable. "is A more accurate measure would be to collet a mine sample over a 34 hour periot, allowing the calcalation of txation rates of urine nelabolites." However, llis is not practical, particularly when testing for drug use in sport.

The sermon androgen response to exercise in athletes can vary according 10 the tyk duration, and intensity of the exercise lask. ${ }^{356}$ Serum concentrations of icstosterone, androstencdione, and dehydroepiandrosterone blecte with shon tern, intense exacise as the result of increased testicular producnon by an moknown mechanism." An increase in serum tustosteront afle exerce may also be cansed by a decrease in the plasna vohme ${ }^{3.9}$ or a dectease in hepatic clearance ${ }^{5 *}$ the effect of exercise on semm oestrogen is also extremely vaniallo."

"A urine spacimen collected ofter high intensity exercises could have a highar concontration of $\mathrm{NA}^{*}$

It is concevable that the incose in circulating androgens in pople parlicipating in shont doration, high intensicy exerdise could result in the stimulation of the aromatase encyme complex, resulting in an absolute morease in the amomit of NA in the urint. Therefure, there are suffichentata ${ }^{37}$ to stggest that a urine specimen collected after high intensity excrise cond have a higher concenuation of $\mathrm{NA}$ for reasons other than delyogration.

\section{Trauma and hypoglycaemic stross}

As yet, no study has investigated the possible effect that traumatic stress (monsculoskeletal injury) may have on 19 norsteroid metabolisu. Interestingly, wo international male alletes, one an international rugby player" and the oller a paralympian (1) Vrasure, personal communication). recently rested positive for $\mathrm{NA}$ above $2 \mathrm{mg} / \mathrm{ml}$, after bol having snfered significant injuries just before passing a urine sample for ang resing. Both athletes climed to be innocen of a doping offence. The concentration of $\mathrm{NA}$ in the minc samples of both athletes was about $6 \mathrm{ng} / \mathrm{mn}$, which is shghty above the 10C cul of concentration for men $(2 \mathrm{mg} / \mathrm{mll})$.

Romik of als have provided some insiglr into lhe effect of a stress response on mandrolone merabolism. Hypoglycamia was induced in 10 subjects by intravenons injection of 0.1 IUky insulin. Unine samples were collected at $0-2,2-4$, ard 4-10 hours after the insulin injection. They conchided that hypoglycaemic stress did not siguificantly alter NA excretion. However, inspection of their data shows that, in cerlain subjuts. NA excretion increased in the first two lours after minoton of the hypoglycamic stess. Wad the study included more than 10 subjects, it is likely that there would have been suffeide statistical power to show that the increase in $N A$ in the first two hours after hypoglycaenic stress wond haye po duced a significant finding. Jypoglycaemestress is associated with the production of glucose counter-regulatory hormones: contisol, glucagon, growth homone, and adrenaline, Cortisol is produced in the adrenal cortex when stimulated by adrenocorticotophic hormone. line kater also stimulates the production of androgens and mineralocorticosteroids from the adreral cortex. ${ }^{3}$ It is tempting to speculate llat the increased production of adrenal androgens results in in crased $N A$ exorenon as destribed above. Futher studies nect 10 evaluate whether the morease in adrenal androgens and their aromatisntion could produce any changes in $N A$ excretion after tramuatic nusculoskeletal stress.

\section{Mineral cotactors and herbal products}

There is also a theoretical argment that certain substances not prohibited in sport may alter nandrolone metabolism. For example, the trace element zinc is a cofactor in many enzymic processes in the body. An increase in scrmm testosteronte in men who are marginaly zinc deficht has been shown after

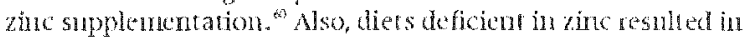
a significan decrease in sermo lestosterone concentration. Wherefore in can be concluded that zinc suppons restosteron production." Althongh there is a lineat relatouship between sermu zinc and sermm lestosterore concenuations, it is not known whether supraphysiological doses of zinc ane associ. ated wh higher levels of lestosteme producton. Certain ahletes are marginally zinc deficient $t^{\text {ta }}$ because of inadeyuate intake ${ }^{63}$ and considerable swean loss. ${ }^{\circ 0}$. As zinc status nay not be optimal in these athletes can finc supplenentation whance testosteronc production and could this morease in testosterone probluction increast the production of aronatisalion intermediates? This question was partially addressed whell a ginc/nagnesinu supplement (30 $\mathrm{mg}$ zine) was given to fooball phyers nightly for eight weeks. This reatment incteased frec and bound serum lestosterone by about $33 \% \%^{\circ}$ These findings were not atributed to hemoconcentration because the blood samples were taken 24 hours alter exercise. On the basis of the possibiliry that 19 -norsterdid metablism nay be associated whin testosterone netabolism and the aromatisation process, it is feasible that zinc supplementation, combined with exercise, may increase ramdrolone motabolics in the uringt,

The herbal product tribulus terrestris (tribestan), which has been used in Eastem culmes since ancient limes 10 treat inpotence and improve libido, is anorler subtance that has been associated with an increased semm testosturone concenuation (S Milanov, nupublished work). Conld tribestan in combination with exercise increase $\mathrm{NA}$ in the urine? Fur ther rescarch is necessary.

\section{CHALLENGING THE IOC CUT OFF CONCENTRATION FOR URINE NA}

Until recently, studies involving lange numbers of sublects to deternine the physiological tange for the concentration of $\mathrm{NA}$ in the urint of then and women free of texogenous nandrotone were lacking. Data on the range of $N$ A conld only be drawn from the andysis of wine from sedentary and recreation people at rest. is at "Whe rotal number of subjects from all these studies is about 150. No specific mention is made in any of the studies of the age of the lnalk suljects. This is relevarn becanse testosterone production decreases with advancing age. Therefore one might expect 19 -norsteroid production to decrease also with advancing age, making the age of smdy populations an irmportant consideration. The amount of $\mathrm{NA}$ in the wine thom the subjects did nor sxced 11 ng/ml except in the sindy of Galan Martin et al, the concerns in which have already been raised.

\section{"There is no explanation by the $10 \mathrm{C}$ of why the threshold concentration for NA is higher in women."}

Hwo recent studies involving hager numbers of sportsmen have provided further evidence. Urine samples collected after exercise in these subies showed that the concentration of $\mathrm{N} A$ in the urinte increased, and in certain nom the concentration of $\mathrm{NA}$ Was close to the cut off concentration of $2 \mathrm{ng} / \mathrm{nd} .^{27}$ Should this be conbinet with other stressurs and posible smpplement intervertions (mentoned above), the concentm. rion of $\mathrm{NA}$ in the urine is most mupedictable.

The loc have also apparenty collected data and measured NA urine excretion in bite male and lemale alletes at the 1996 Nagano olympic ganes, but llese dara lave not ben refrased into the mublic domain ${ }^{\text {st }}$ It would be beneficial for the Ioc data to be made public to suppont reasoning behind the calculation of cut of conceutrations for $\mathrm{NA}$ in the wite of wen and wonen. There is also tho explanaton by the $10 \mathrm{C}$ of why the threshold concentration for $\mathrm{NA}$ is higher in women. If 
the reason for it is the higher circulating levels of oestrogen, Jarthularly at the lime of ovulation, is this not indirect support for the presence of 19 -norsternids as intermediates in the an onatisation of androgens to oestrogen? ${ }^{\text {is }}$ Bradfodd-Hill has stated: "It is the essence of science to disclose both the data unon which a conchnsion is based and the methods by Which the conclusion is obtained"."

The IOC has defended the status quo on nandrolone and confind these threshold valnes of 2 nghul in men and 5 $31 \mathrm{~g} / \mathrm{nl}$ in women in Monaco in October $1999 .{ }^{70}$ The conditions of strict liability are currently applied in the case of any athlete contravening, the above thresholds.

\section{METHODS TO TEST FOR NA}

A solution to the cont roversy surrounding nandrolone in sport is to develop a testing procedure that can accuratcly differen. tiate emologenous nandrolone merabolites from nandrolone that is ingested or injected. The technique of gas chronatography combustion-isolope ratio mass spectroneny (GC-C-IRMS) to calculate the "G/2 $\mathrm{C}$ ratio is currenty being developed as a method to fulfil this purpose. ${ }^{\text {n. } n 3}$ This is based on the pinciple that natural steroids have a different corbon isolopic signature from syuthetic steroids. The " $\mathrm{C} / \mathrm{C}$ ratio for synthetic nandrolone metabolites is lower throm that for endogcuous metabolites, therefore administering exogenons nandrolon" will lower this ratio. This ratio has also teen proposed as a method of defecting the use of synthetic restoster. one as an alternative to the testosterone/epitestosterone ratio." "fowever, a potentiol problen wilh GC-C-IRMS is the lack of reproducibility and sensitivi ty because of the low levels of endogenous nandrolone inctabolites present in the body. At prescit, this rnethod can only be applied to "high" concenura. tions of $N A(60 \mathrm{ng} / \mathrm{mu})$ in the mine. ${ }^{73}$

le Bizec $a^{t} a^{7}$ lins proposed examining the steroid compugates as an additioual criterion to distinguish between the endogenuts or exogenous origin of mandrolone metabolines. tudogenous NA was found to be $30 \%$ sulpho-conjugated inl contrast with administered nandrolone, which was fomd to be $100 \%$ conjugated to glucuronic acid when excreted in the urine. ${ }^{24}$

Kintz ef a $7^{1 / 2}$ proposed that analysis of hair samples from alletes is another option to consider for detecting the presence of exogenous nandrolone. The analysis of hair sam. ples could be used to accurately verify positive result s obained by gas chionatography-mass spectrometry.

Until the hair sample and GC-C-IRMS techniques have leetn validated on a large scale, a mudent approach after the defection of NA in urine samples above the cut off concentra. tion is for the ahlere to have further blood rests before the sample is declared positive, as is done for athletes with a ligh restosterone/eptestosterone natio.

\section{CONCLUSION}

The abuse of the steroid lest osterone present a a new problem for ding control in sport. ${ }^{2}$ Perhaps the same can now be said for nandrolone. According to the olynuic movement anti doping cole, NA is not a prohibited sulstance." However should $\mathrm{N} A$ in the urine exced a certain threshold concentra tion, the interpretation is that nandrolone has been ingested or injected. There is strong scientific evidence to show that NA can appear in the urine of people free of exogenous llandrolune. Fvidence snggests that NA ray occur as an intermediate in the aromatisation of testosterone to oesnogen Recent evidence has shown that the amount of $N A$ in the urine can be regulated by the administration of human chori onic gonadotrophin. "lherefore, threshold concentrations for uken (2 $\mathrm{ng} / \mathrm{ml})$ and wonter $(5 \mathrm{ug} / \mathrm{ml})$ as defined by the $10 \mathrm{C}$ are srill open to debate because conclusive scientific evidence showing how these values nay be altered by various pliysiological stinuli is heking. In accordance with this,

\section{Tots home mesegre}

19-Norandrosterone (NA) is produced endogenously as an intermediate in the aromatisation of androgen to oestrogen. Intense exercise moy increose its concentration in the urine. Future laboratory lesting methods need to distinguish endogenous from exogenous nandrolone metabo lites accurately, as this has important implications for doping control in sport.

multicentre shdies need to answer further specific questions on the current urine threshold concentrations for mandrolime metalolites and whetler physiological stressors and jermit ted supplement interventions can alrer NA excretion.

\section{Authors' affiliations}

R M N Kohlar, MI Lambert, MRC/UCT Reserich Unil for Exercise Science and Sports Medicine, Department of Human Bislogy, University of Cope Town, Sports Science Instituie of Souht Africa. Newlands, South Africa

\section{REFERENCES}

1 La Bixec 8, Montagu F, Gaudin 1, at al. Evidenca for the presence of endogenous 19 nororandrosierone in humari tritie, Jound of Chromatogrophy $81999 ; 723: 157-72$.

2 Ryan A. Anabolic androganic staroids Borlin, Heidalberg

Springar-Varlag, 1976:515-33.

3 Dollors $C$. Therapoutic drugs. Edinburgh: Chuchil

Livingstone, 1981:2:N25-9.

4 Houpt HA, Rovera GO. Anabolic staroids: a raviaw of the liberotura. Am Sporis Med 1984:12.469-84.

5 Lambert Mi. St Clair Gibsan A, Anabolicandrogonic staroids; afferds on musclos sizo and strangth. Sowh African Journal of Sports Medicina $1995 ; 2: 6-9$ 6 Titlested SD, Lamber MI, Schwallnus MP. A survey to determine types
and dosages of anabolic androgenic stepoids used by competitive and dosegess of anabolic androgenic stapoids used by competitive bodybuilders in

$1994 ; 1: 24-8$

7 Hickson RC. Bdll KL, Foldua MT. Advarsa sffacts of anabolic storoids. Mad Toxicol Adversa Dug Exp 1939:4:254-7

8 Bjorkhem E, EKH. Detection and quantitation of 19 -norandrastersme in urine by isotope dilutionmass spectramety. I Steroid Biochan Mol Biol $1982 ; 17: 447-51$

Q Bolkwin L, Shurmeyer T, Hano R, of ol Pharmocokinalics of 19-nonestostarone asters in normal men. J Storold Biochena Mol Biol $1085 \cdot 22: 623-9$.

10 Masse R, Lalibaita C. Tremblay L, of Gas chromatographic/mass spectrometric analysis of 19 nortestosterone urinary malabolites in man spactrometric analysis of 19-nortestosterone

11 Debruychere $G$, de Sagher $R$, De Leenhear $A$, al al. The impact af nandrolene matabolites accurring in normal mole urines, on the cutolt level stipulated for nandrolone doping. hn: Gorog S. od. Proceedings of tha fourth symposium on the anolysis of steroids. Auryush 1900 , Budapes? Budapest: Perc, Akademia Kado, 1990.363

12 Shanzer W. Donike M. Metabolism of anabolie staroids in mon: synthesis ond use of referenes stybstances for identification of anaboliz steroid melobolites. A radylica Chimica Acto 1993,275:23 48.

13 Ozar D. Terrizer A. The determination of nandrolones and its melabolites in the urine by gas chomatagraphy.mess spectromein. Eu J Drug Mekb in the unine by gas chromatography

if Ayotto C. Nutritaral supplements and doping controls. IAAF Naw Srudies in Athiosing 1990:14.37-42

15 Dehentin L Bennaire Y, Plou $P$. Uninary exeration of 19 morondrostar one of endogenous arigin in man: quantitative andys is by gos chromatography-mass spectromelry. Journol of Chromatography $1909 \cdot 721: 301-7$

16 Urolets V. Gillette P. Overthe counter $\Lambda^{5}$ andbolis steroids

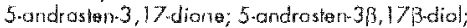
dehydroepiandrostarone; and 19 nor.5androstan 3 , 17 .dione: excration studies in men, J Anal Toxicol 2000,24:180-93.

1) 5 argura I. Later of information to the heads of $10 \mathrm{C}$ occredilad laboroboras. Barcelona, Auqust $22190 \%$

18 Cotlin D Ledar B. Ahrens B, al al. Traca contamination of overthe counter undrostenodione and positive urine tesl resuls for a nondrolone metabolite. JAMA 2000284:2518-21.

19 Debruyckere $G$, Van Peighem $C H$. Influence of the consumplion of meat contaminaled with anabolic steroids on doping lasts. Andylica Chistice Acta 1993;2\%5:40-56.

20 La Bize B. Goudin I, Mantaou F, at al Consequanes of boor adibla lissue consumphion on urinory profiles of nondrolone metiobolitas. I. Mass 


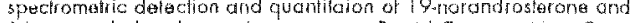
19-naratocholamolone in humon urina. Ropid Commun Mass Spectron $2000 ; 14: 1058-65$

21 Kionan AT, Brooks RV. A codioimnunocssay for the metabolifes of the anabolic staroid nondrolone. I Fhom Biomed Anal 1980;6:473..83. 22 Dobruyetiare $G$, da Saghar R, Von Palaghem C. Clostabolpositiva urine

23 internetionsl Olympic Committent. Criserica for reporting law concentrations of anobolio storoids. International Olympic Commithen documeni. 1998: Aug l;appendix A.

24 Kintz P. Cirimala $V$ Ludes B. Norandrasterone and Noretiodholarolone: mutabolite markers. Acta Clin Belg Suppl 1999;1:68--73

25 Rezsilk $Y$, Dehannin $L$, Coffin $C$, et al. Urinary nondrolane metabolitas of andogenous orgin in mans a conlismation by output regulation undar humon chorionic gonadorophin stimulation. $J$ Clin Endocripol Molab $2001,86: 146-50$

26 Vun Eanoo P. Deibexa FT, de Jong FH, at at. Endogenous origin of norantrosterona in female urine: indirect evidence for the production of 19 norstersids as byproducts in tha conversion from androgan to 19-norstersids as byproducts in the conversion from and
ostrogen. ISteroid Biochem Mal Biol 2001:78:351-7.

27 Rubinson $N$, Taroni $F$, Saugy $M$, af al. Detection of nondrolone meabolies in urine after a foobal game in professional and amasen players: a Boyezian comparison. Forstnsic Sci hin 2001;122:130-5.

28 La Bizac B, Bryand F, Goudin l, at al Endoganous nandrolona matabolitas in human urine. Two yaar moniloring of profassional socest melo ployers. / Anal Foxicol 2002 rin press.

29 Golun Mortin AM, Moynar Marino J, Garcia de Tiedro MP. et al. Delermination of nandrdone metabolitas in urina samples from sedentary parsons and sporismen. J Chramatogr B Biomed Sci Appl porsens and sporismon.
$2001,761: 229 \ldots 36$

30 Fishrnan J. Biochamical machonism of aromalisation. Cancer Res 1962:42:3277-.80.

31 Longeope C. Kalo T. Hortan R. Conversion of blood androgens to - atrogers in normol aduli men and women. 1 Clin inves 1969:48:2191-201

32 Ganong WF. Rovew of madical physiology. Connaclicut, USA: Lange Medical Books, 1999,17:283,19:345-80.

33 sulcova d, Rafler I, Siuka L. 19 nortesiosterone in mouse kidney. Endocrinol $E_{x p}$ i $97 \% ; 3: 225-35$

34 Milowich J. Axalrod A. Testosterone metabolism by placental microsomes from baboons: identification of 19 -nortestosterene and 18-nor-4androstarmdione. J Staroid Bio ham Mol Bioll $979 ; 10 ; 241-3$.

35 Dohannin L. Jondat M. Schollar R. Androgen and 19 -norstercid protites in human provulatory follides from stimulcied cycles: an isolopa diluion mass spectromatic study. J Sterod Biocham Mol Biol 1937 26:399-405

36 Raznite Y, Herrou M, Deluannin Le of Rising plasma lovels of 19 nortestesterone throughout pragnancy" datermination by radioimunoassay and validalion by gas chromatographymass spectrometry. I Chin Endocrinal Metab 1987:64:1086 8

37 Urahots V. Gillette P. Over-the-counter anabolic steroids 4 androsian-3,17 diona, 4 androsten $3 \beta, 17$, diol and 19.nor-a androsten-3,17diona: excretion studies in man. / And Toxicol $1090,23: 357-60$

38 Makin HJL. Biochamisiry of slarcid hormones. Blackwall Scientific Publicotions 1975:11:250-71.

39 Hagonsen-J atne AH, Misund J, Hemmersboch P. Detorminatian of vinary norandrastarone excretion in fanales during one manstrual cycle

40 Marock-Engalko U, Gayer H, Schanzer W. Rocent artarnos in dopirg analysis Cologne: Sport und Buch Strauss, 1998:119.

41 Smols AGH, Pieters GF, Lozokool DC, at al Dissocigled response of plasma testosterone and 17 alpha-hydroxyprogesterone to a single or repacled human chorionic gonadoropin administration in norenal man. Cin Endocrinol Matab 1980;50:90

42 Kieman AT, Brooks RV. Collyer $\mathrm{SC}$ at at Crtaria to indicote pastosiarone odministration. Br I Sports Mad 197024:253-64.

43 Cowan DA, Kicmon AT. Walker $C$, al. Elect of adminisirction of human chorionic goncdotrophin on criteria used to assass festosterono
administration in athlates. J Endocrinol $1991,131: 147-54$.

44 Padron RS, Wischusen J, Hudson B, of of Prolongad biphosic rasponst3 of plasma tesiostarona to a single intramuscular iniaction of human of plasma tesiostarone to a single intramuscular inischion of huma

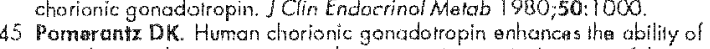
genadotropic hormones to stimulate eromatisation in the testis of the rat. Endocrinology 1981;109:2004

46 Ladar 1 , Longcope C, Collin D, ot al Oral andrastanedione administration and serum lestosterone conoentrations ins young men. JAMA 2000;283;779-82.
47 Howon , Tcte J. Androstenedione production and the interconversion roles mecsurad in the peripheral blood and studies on: the possibite sile of comarsion to tastostarone. J Clin invast 1996:45:301-13.

48 Barkovitz GD, Guerami A, Brown TR at di. Familiol gynacomosta with increased extraglandula aromatisation of plasmo cabon, stercids. I Cin Invesf 1985:75:1763-9.

49 Gillias $H$, Derman $W$, Noakes $T$, at af Psoudoaphedrine is without argogenic effecti during prolonged axercise. 3 Appl Physiol $1996 ; 81: 2611.17$

50 Sutton IR, Coleman MJ, Casey JH, at al Androgen rasponso during physical axercise. BMI $1973 ; 1,520$.

51 latmb DR. Androgens and exescisa. Mad Sci Sports 1975;1:7.

52 Sthmitt WM, Kindermann W, Schnobel A. Testosterone blood lovel and physical axercise. In / Sports Med 1082;22(suppl):81.

53 Vino A. Hormones in muscular adivily. Baca Ratom, Fl.CRC Press, $1985,4: 35$-.

54 Vogol Pe Increase in free and lotal festasterone during submoximel exercise in normal moles. Merd Sel Sport Exare 1985;17:119-23.

55 MecConnie SE, Bokan A, Lampenon RM, af al. Decrasad hypolholamic

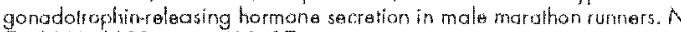
Engl / Mad 1986:315:411-17

so Kramer RR, Kitgore J., Kramer GR, of al. Growth hormono, 1 Gr-1 and lestosterone response to restrictive exercisa. Mad Sai Sporls Exarc $1992.4: 134652$

57 Cumming $D$, Brunsting $L$, Strich $G$, at al. Reproductive hormane incrense in response to acule axarcise in men. Med Sci Sports Exerc

58 Wilkerson JE. Horvath $5 \mathrm{M}$, Gutin B. Plasma restosterona duing readnill axercise. I Appl Physid 1980;49:249.

59 Nol S. Springbok rugby player lests positiva for steroids. Cape Timas 2000 Nov $3: 26$

60 Prasad AS Manizoros CS. Back FW, at al. Zine slutus and serum tessesterone levels in bedithy adults. Nufrition 1996:12:344-8.

d) Castro-Magnan $M$, Collipp P, Chen $S$, of ol Zine wutritiond status, androgens and growth relardation. Antorican Journal of Diseases in androgens and growth rolar

62 Khalad S. Brun JF. Micallol IP, at ol Serum zinc and blood hoology in sportsman (footbcil players). Clin Hamaheol Microcirc 1897,17:47/-53. 63 Hawley J, Dennis S, Lindsay $F$, at al. Nutritional proctices of ahlalus: are thay sub-optimal? \& Sporfs Sci $19,55,13,575-81$.

64 Clarkson PM. Minerrals: exerclse performance and supplernantation in whlotes.J Sports Sci 1991:9:91-116.

65 Cordove A, Navas FI. Eftect of praining on zine molobolism: changes in serum and sweat zinc congantrations in sportsmen. Am Nulr Mefoes $1998 ; 42: 274-82$

$6 \delta$ Brilla LR, Conte V. Effect of a novel zinemagnesium formulation on hommones and stranght. Jound of Exeraiss Physidogy $2000 ; 3: 26-36$

67 Lewis JG Ghanadion R. Chisholm GD. Sorum dihydrotastostama and testostarone chonges with age in man. Acta Endocrinol $1976,92: 444-8$. 68 Jamas VHT. UK Sports Council nondratone revitow. London: UK Spots Conmeil, January 2000 .

69 Morgan WK. On ovidanca, ambellishmant and afticacy. J Eval Clin proo $1997 ; 3: 117-22$.

70 Suugy $M$, Robinson $N$, Cardis $C$, al al Nandrolone matobolihes in Pormat compatition rests. FIFA Sports Medical Carmmittee

7) Shackloton $\mathrm{CH}$. Phillips $\mathrm{A}$. Chang $\mathrm{T}$, at al. Confirming testostarono administration by isolope ratio mass spectromatric analysis of urinary androstanediols. Staroids $1997 \cdot 62: 379.87$.

72 Sharkloton $\mathrm{CH}$, Ratman E. Phillips A, at al Andrastanediol and 5 -androstenediol profling for delecting exogenously administered

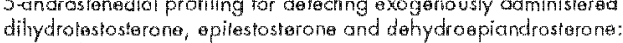
polential use in gas chromalography isolope ratio mass spectromatry. Steroids 1997;32:065-73.

73 Mathurin JC, Herrou V. Baurgogne $E$, st al. Gas chramatographycombustion: sotopa ratio mass spactrometry andysis of 19-norsteroids: application to the detection of a nandrolone materolita in urine. J Chronatogr B Blomed Sei Appl 2001,759:267-75.

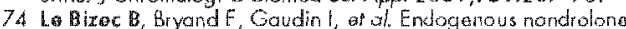
makabolitas in humon urina. Proliminery rasults to discriminate belwoon endogenous and exo genous origin. Sperolds 2002;67:705-10.

75 Kintz P. Hair tesing and daping control in sport. Foxicol Lat

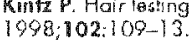

76 Kintz $P$, Cirmela $V$, Dumestre Toulat $V$, at al. Doping control for nondroleno using hair andysis. J Phom Biomed Anal $2001 ; 24: 1125$ 30.

77 Olympic Movement. Oympic Movemant antidoping cade 1999: Aponatix A: prohibitad dosses af substancss and prohibited methods Switzarland: OOC Las same, 2001 


\begin{tabular}{|c|c|}
\hline 唩 & 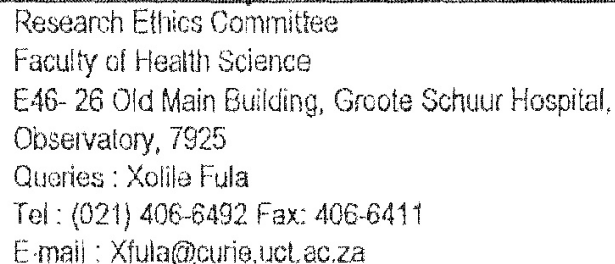 \\
\hline
\end{tabular}

8 March 2002

REC REF: 034/2002

Prof MI Lambert

Human Biology

Dear Prof Lambert

CAN ACUTE SEVERE MUSCULOSKELETAL TRAUMA AFFECT THE EXCRETION OF NANDROLONE METAEOLTES IN THE URINE

Thank you, for submitting your study to the Research Ethics Committee for review.

It is a pleasure to inform you that the Committee has formally approved your study.

Please quote above Rec reference number in all correspondence

Yourşsincerely 